Supporting Information for

\title{
Ozone-Mediated Amine Oxidation and Beyond: A Solvent Free, Flow- Chemistry Approach
}

\author{
Eric A. Skrotzki, Jaya Kishore Vandavasi, Stephen G. Newman* \\ Centre for Catalysis Research and Innovation \\ Department of Chemistry and Biomolecular Sciences \\ University of Ottawa \\ 10 Marie-Curie, Ottawa, Ontario, Canada, K1N 6N5. \\ *E-mail: stephen.newman@uottawa.ca
}

\section{Table of Contents}

\section{Contents}

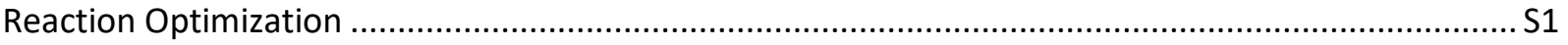

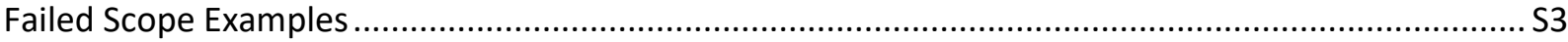

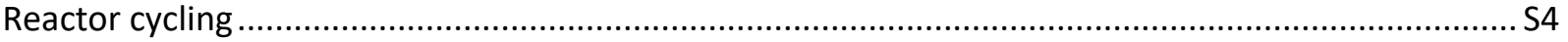

Direct Comparison with Literature Precedent:................................................................................. S5

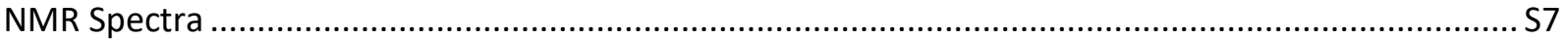

\section{Reaction Optimization}

We began our exploration into this topic by using dodecylamine as a model substrate using the reactor setup illustrated in Figure S1 below. With this, various ozonation times and temperatures were screened to determine optimal conditions (Table S1). It was previously known that these types of oxidations have taken place at $-78^{\circ} \mathrm{C}$, but our system allowed us greater control over specific temperatures than a simple dry ice bath. It was found that $-60^{\circ} \mathrm{C}$ gave the best balance between selectivity while still enabling the desired reaction to proceed quickly. The next variable to be optimized was time, and 15 minutes proved to be the point at which yield was highest, even though some starting material was still recovered. If the reaction is left to continue for longer, degradation pathways will begin to outcompete product formation. 


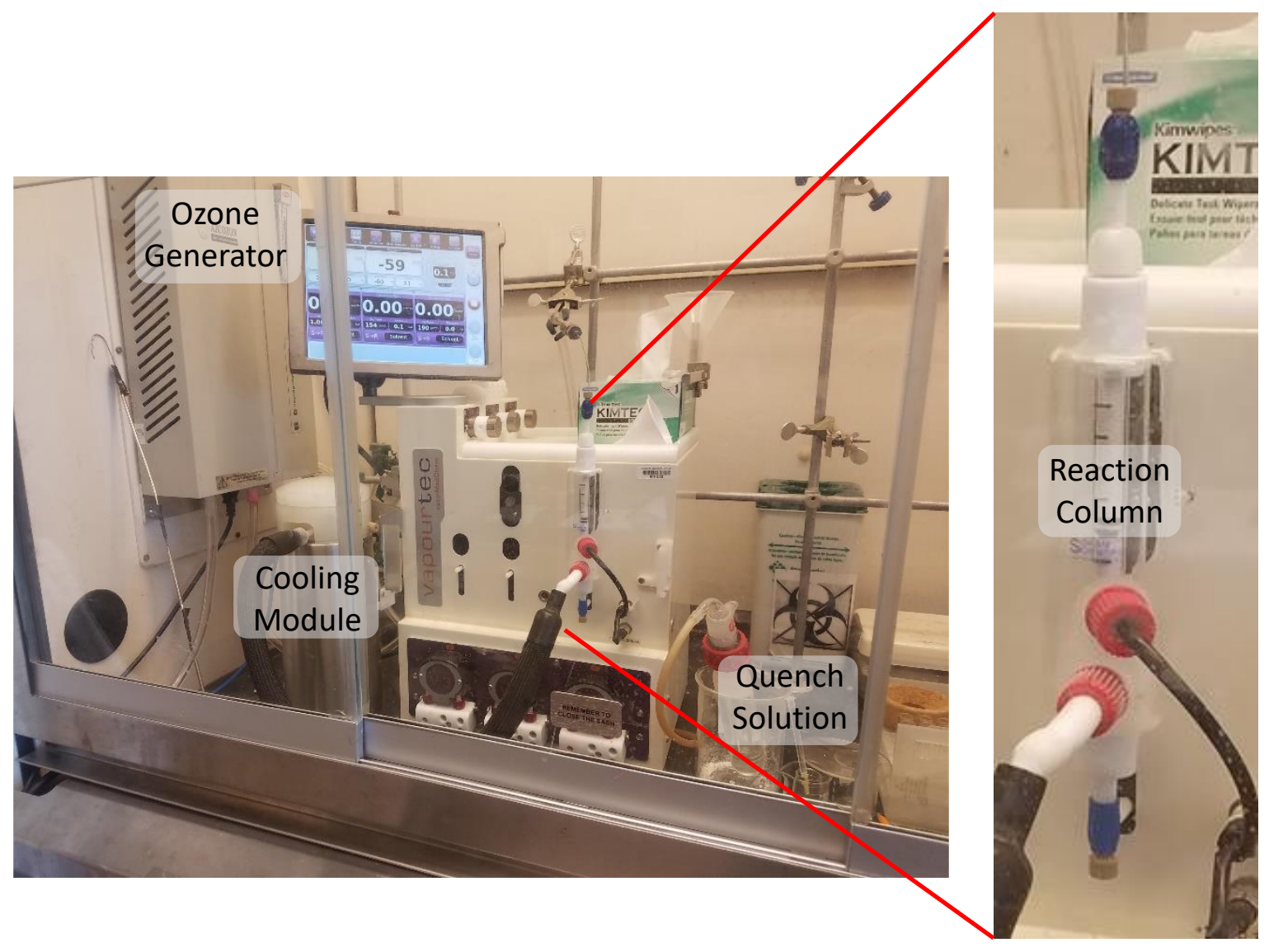

Figure S1: Photograph of the complete reactor setup 
Table S1: Optimization of Ozonation Time and Temperature ${ }^{a}$

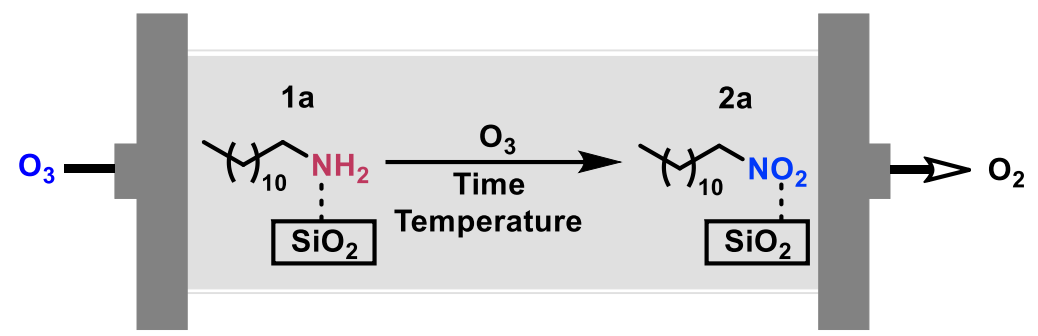

$\begin{array}{ccccc}\text { Entry } & \begin{array}{r}\text { Temperature } \\ \left({ }^{\circ} \mathbf{C}\right)\end{array} & \text { Time (min) } & \text { Yield }^{\mathbf{b}}(\%) & \begin{array}{c}\text { Amine Recovery } \\ (\%)^{\mathbf{b}}\end{array} \\ 1 & -40 & 10 s & 11 & 47 \\ 2 & -40 & 15 & 51 & 25 \\ 3 & -40 & 30 & 42 & 0 \\ 4 & -60 & 5 & 50 & 32 \\ 5 & -60 & 15 & 62 & 25 \\ 6 & -60 & 30 & 49 & 13 \\ 7 & -70 & 20 & 29 & n / a\end{array}$

${ }^{\text {a }}$ Reactions were run on a $0.1 \mathrm{mmol}$ scale. ${ }^{b}$ Yields were obtained via ${ }^{1} \mathrm{H}$ NMR spectroscopy using $1,3,5$ trimethoxybenzene as an internal standard.

\section{Failed Scope Examples}

Notably, two classes of attempted substrates did not yield any product: Electron rich aromatic rings, and substrates containing multiple amines. Our hypothesis for the former is that the increased electron density of the aromatic ring make it more prone to reaction with the ozone. The latter class of substrates failing is most likely due to multiple equivalents of ozone being employed in our method. Each nitrogen can undergo this reaction independently of one another, and so multiple sites of oxidation could increase chances of molecule degradation. As such, no product, starting material or discernable side product were observed with either substrate.<smiles>COc1ccc(CCN)cc1</smiles>

1

$0 \%$<smiles>COc1ccc(CCN)cc1OC</smiles>

2<smiles>NCCCN1CCOCC1</smiles>

3 $0 \%$<smiles>CCN(CC)CCCN</smiles>

4

Figure S2: Failed Scope Examples 


\section{Reactor cycling}

Amine was dissolved in $10 \% \mathrm{MeOH} / \mathrm{DCM}$ solution ( $0.1 \mathrm{mmol}$ amine per $10 \mathrm{~mL}$ of solution). $1 \mathrm{~g}$ of dried silica gel was added to our omnifit column, and attached to the Vapourtec built in pumps. Using the Vaportec V3 pumps, a total of $10 \mathrm{~mL}$ of this solution was drawn added to the omnifit column. The Vapourtec interface was then used to select oxygen flow to remove the solvent and dry the column for a total of 20 mins. Reaction was then cooled and ozonated as described in General Procedure A. Following reaction completion, Vapourtec V3 pumps were used to draw and pump $20 \mathrm{~mL}$ of a 1:1 MeOH/DCM solution. These steps could then be repeated from the beginning.

The reactor cycling set-up described in manuscript Scheme 4 is outlined in more detail in Figure $\mathbf{S 3}$ below. Figure S3A illustrates the flow path (in red) for normal reactor operation for ozonation. Oxygen from a gas tank flows through the ozone generator to the reactor inlet. Passing through the reactor, it exits and flows to a solution of aqueous sodium metabisulfite. Figure S3B illustrates the flow paths for loading the amine solution onto the column (red path), and flushing material off the column (blue to red path). Table S2 illustrates reproducibility over three cycles (Entries 1a-1c). Alternate loading conditions were tested using pentane as the solvent (Entry 2), which resulted in a $0 \%$ yield due to a lack of even dispersion of the amine along the silica length. If the column is not allowed to fully dry before reaction is started, a drastically reduced yield is also observed (Entry 3). Drying the column using either air pressure or heat alone give reasonable yields (Entry 4 and 5).

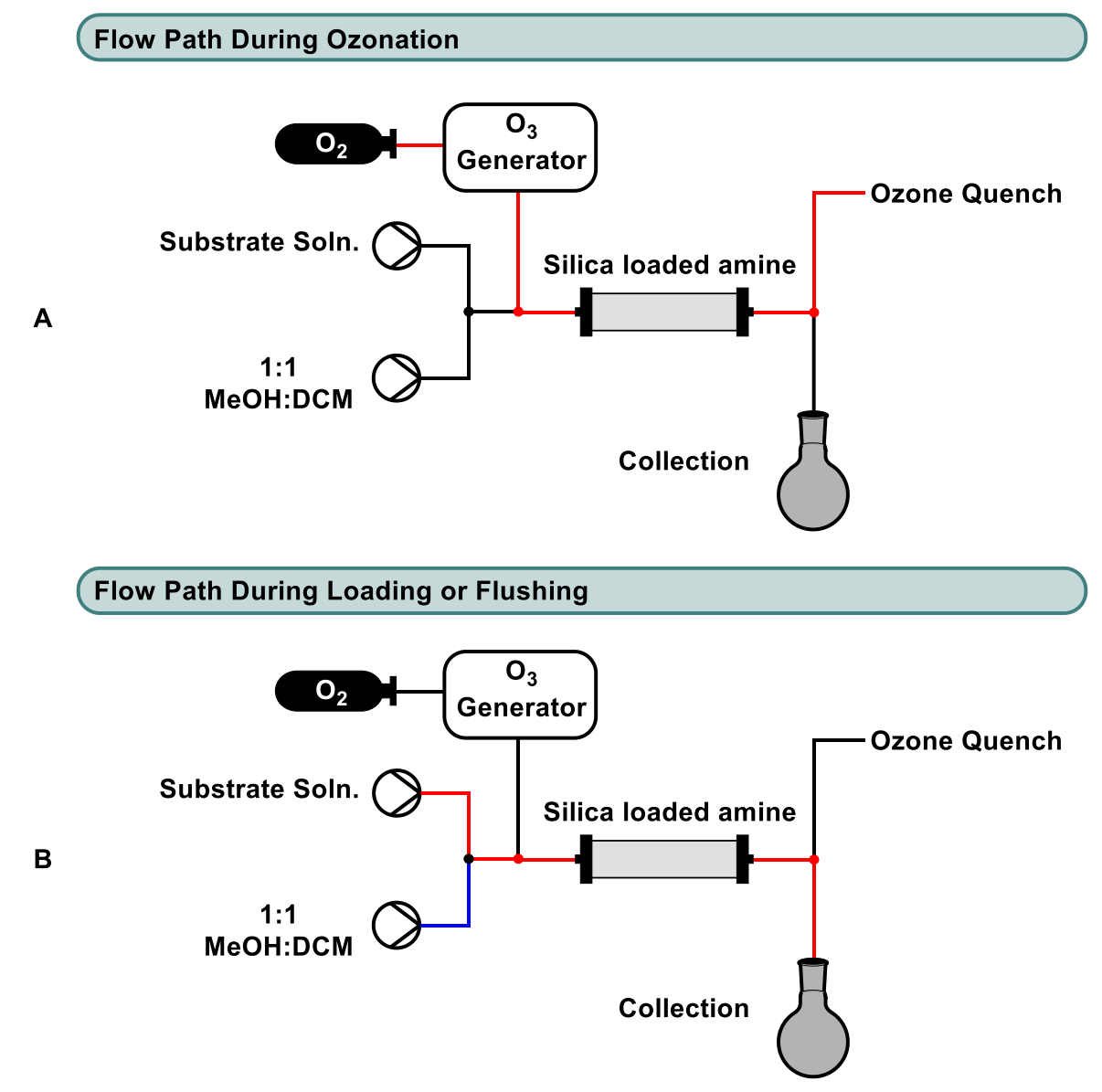

Figure S3: Schematic of Complete Flow Reactor Set Up 
Table S2: Reactor Cycling

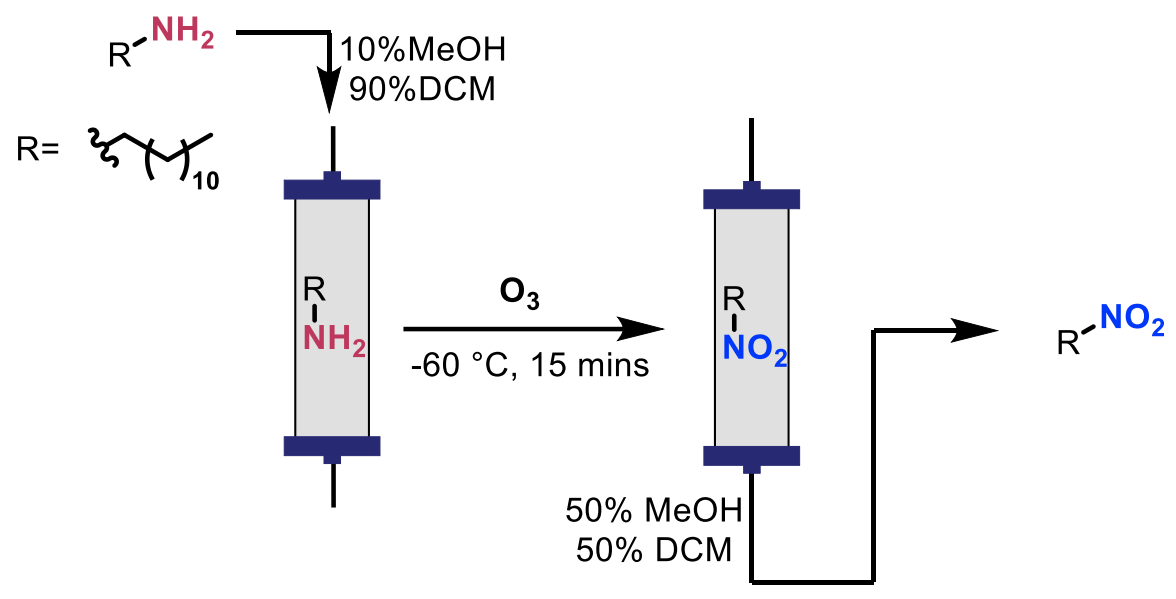

\begin{tabular}{|clc|} 
Entry & \multicolumn{1}{c}{ Deviation from Standard Conditions } & Yield (\%) $^{\mathbf{b}}$ \\
\hline 1a & None - first reproduction & $60^{\mathrm{c}}$ \\
1b & None - second reproduction & $59^{\mathrm{c}}$ \\
1c & None - third reproduction & $62^{\mathrm{c}}$ \\
\hline 2 & Loaded amine in pentane & 0 \\
3 & Column not fully dried & 20 \\
4 & Column dried using heat only & 55 \\
5 & Column dried using air pressure only & 57 \\
\hline
\end{tabular}

a Reactions performed on a $0.1 \mathrm{mmol}$ scale using dodecylamine.

${ }^{b}$ Yields obtained via ${ }^{1} \mathrm{H}$ NMR spectroscopy using 1,3,5 trimethoxybenzene as an internal standard.

${ }^{c}$ Yield $\mathbf{1 a}, \mathbf{1 b}$, and $\mathbf{1 c}$ are performed using identical conditions in triplicate.

\section{Direct Comparison with Literature Precedent:}

In Mazur's seminal 1977 article, the amine oxidation procedure is described as follows: "The amine is absorbed on the silica gel ca. 100 times its weight, by impregnation using a volatile solvent. The adsorbed silica gel is then cooled to $-78{ }^{\circ} \mathrm{C}$ and ozone is passed through it. After warming to room temperature, the product may be eluted from the silica gel with an appropriate solvent."

In an effort to directly compare our new method with literature precedent, two oxidations were performed using Mazur's described method. The first was cyclohexylamine, a substrate that was compatible with both Mazur's scope and our own. The second was using $N$-Boc ethylene diamine, a complicated substrate which we were able to obtain with our new method in moderate yields. When cyclohexylamine was subjected to Mazur's procedure, an identical result to his was observed (Table S3). However, when N-Boc ethylene diamine was tested with Mazur's procedure, only trace yield was detected, proving that it is incompatible with Mazur's method. 
Table S3: Direct Comparison with Literature Precedent

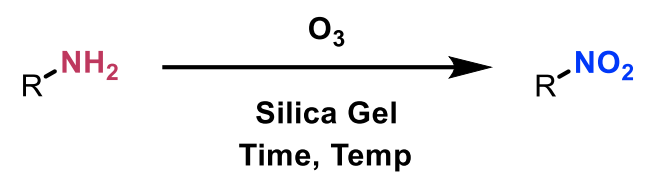

\begin{tabular}{|c|c|c|c|}
\hline Starting Material & Product & $\begin{array}{c}\% \text { Yield }^{\mathrm{a}} \\
\text { Flask reactor }^{\mathrm{b}} \\
-78^{\circ} \mathrm{C}, 30 \mathrm{~min}\end{array}$ & $\begin{array}{c}\% \text { Yield }^{\mathrm{a}} \\
\text { Column reactor } \\
-60^{\circ} \mathrm{C}, 15 \mathrm{~min}\end{array}$ \\
\hline & & 69 & 80 \\
\hline I & & trace & 54 \\
\hline
\end{tabular}

${ }^{\mathrm{a}}$ Yields obtained via ${ }^{1} \mathrm{H}$ NMR using 1,3,5-trimethoxybenzene as an internal standard.

${ }^{\mathrm{b}} 0.3 \mathrm{mmol}$ of amine was adsorbed onto $3 \mathrm{~g}$ of silica gel by dissolving in pentane and removing solvent by rotary evaporation. Silica gel was cooled to $-78{ }^{\circ} \mathrm{C}$ in a round bottom flask and exposed to a flow of ozone for 30 mins before warming and eluting product with ethyl acetate.

c Reaction was performed following General Procedure A. 
NMR Spectra

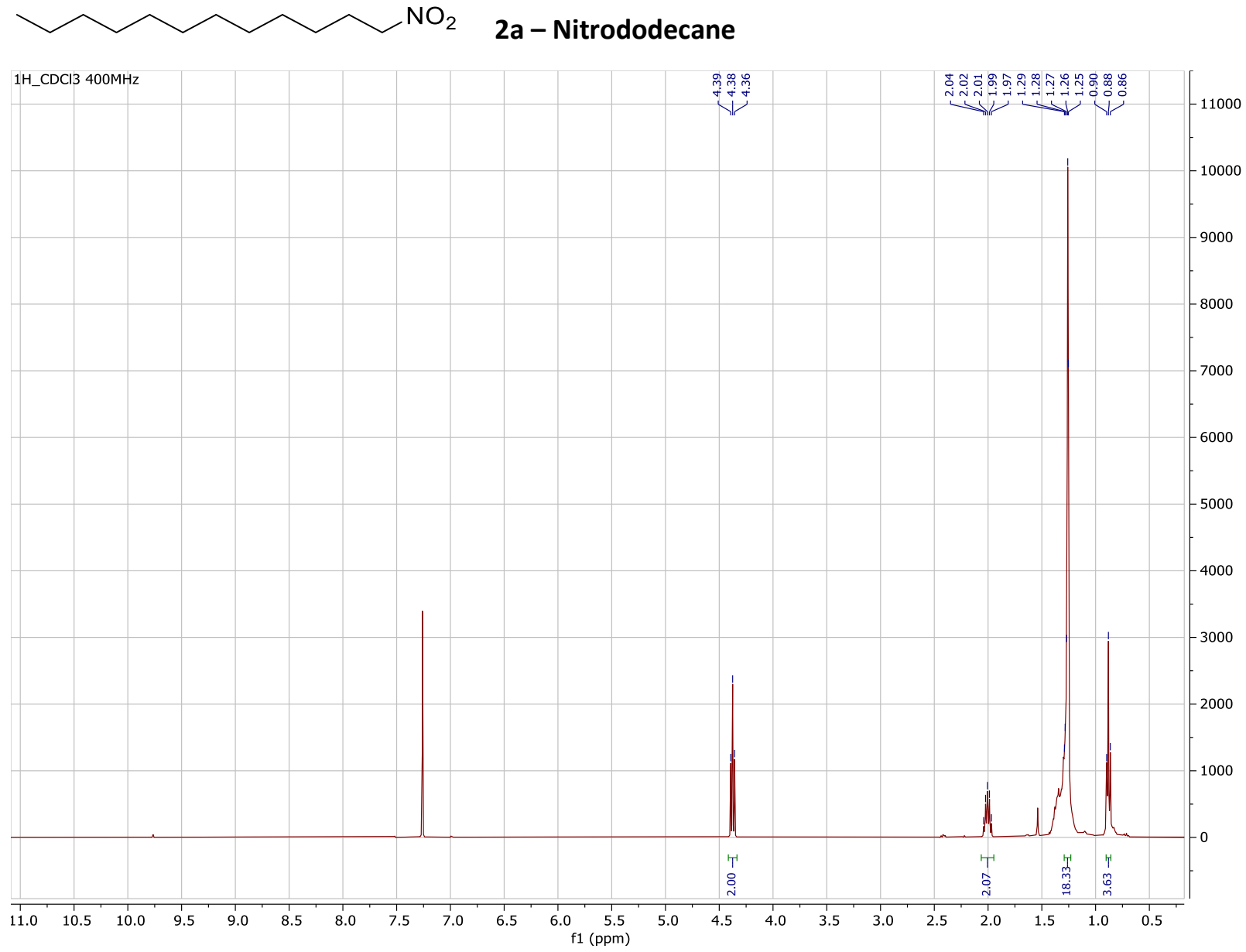




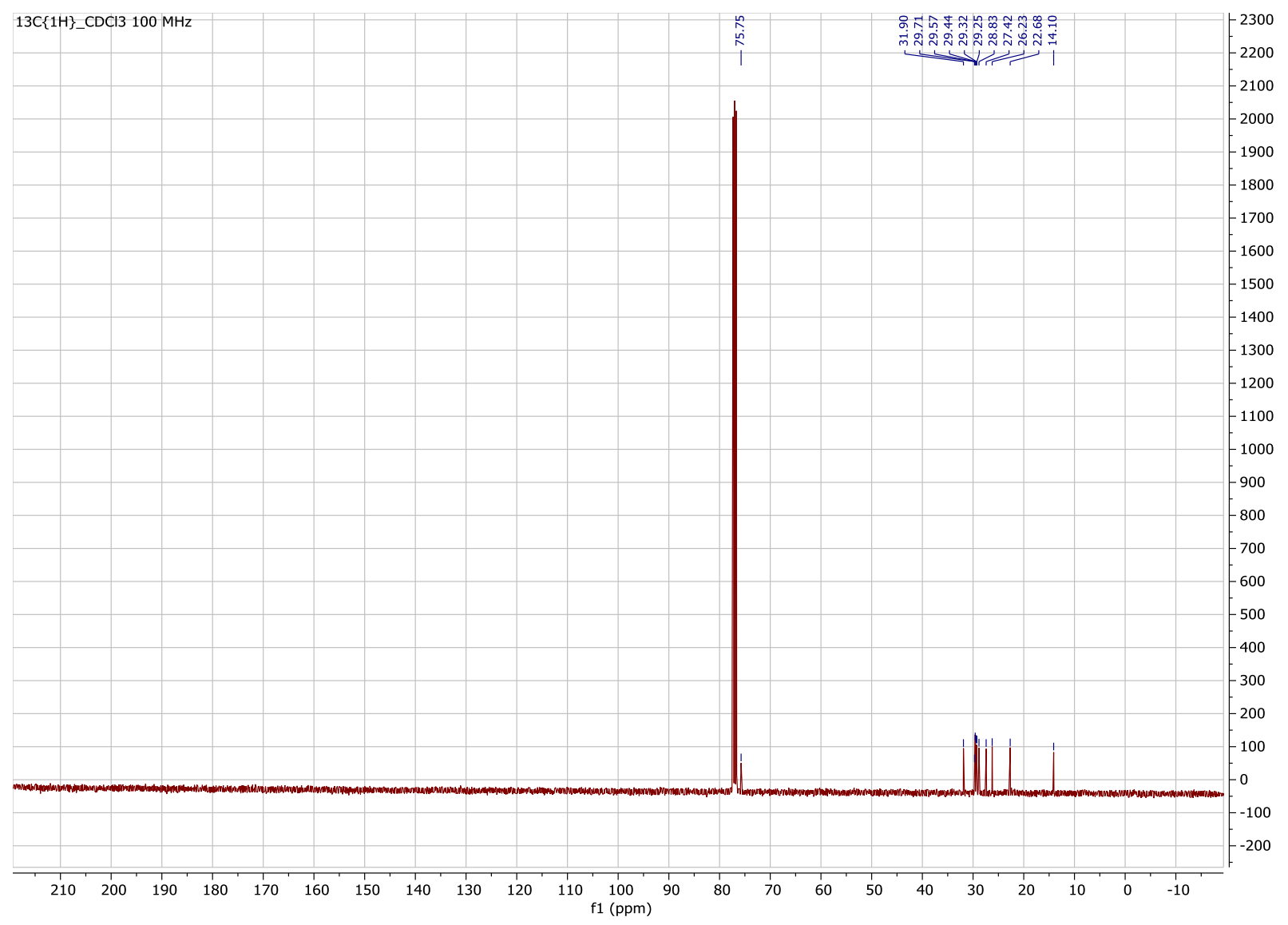



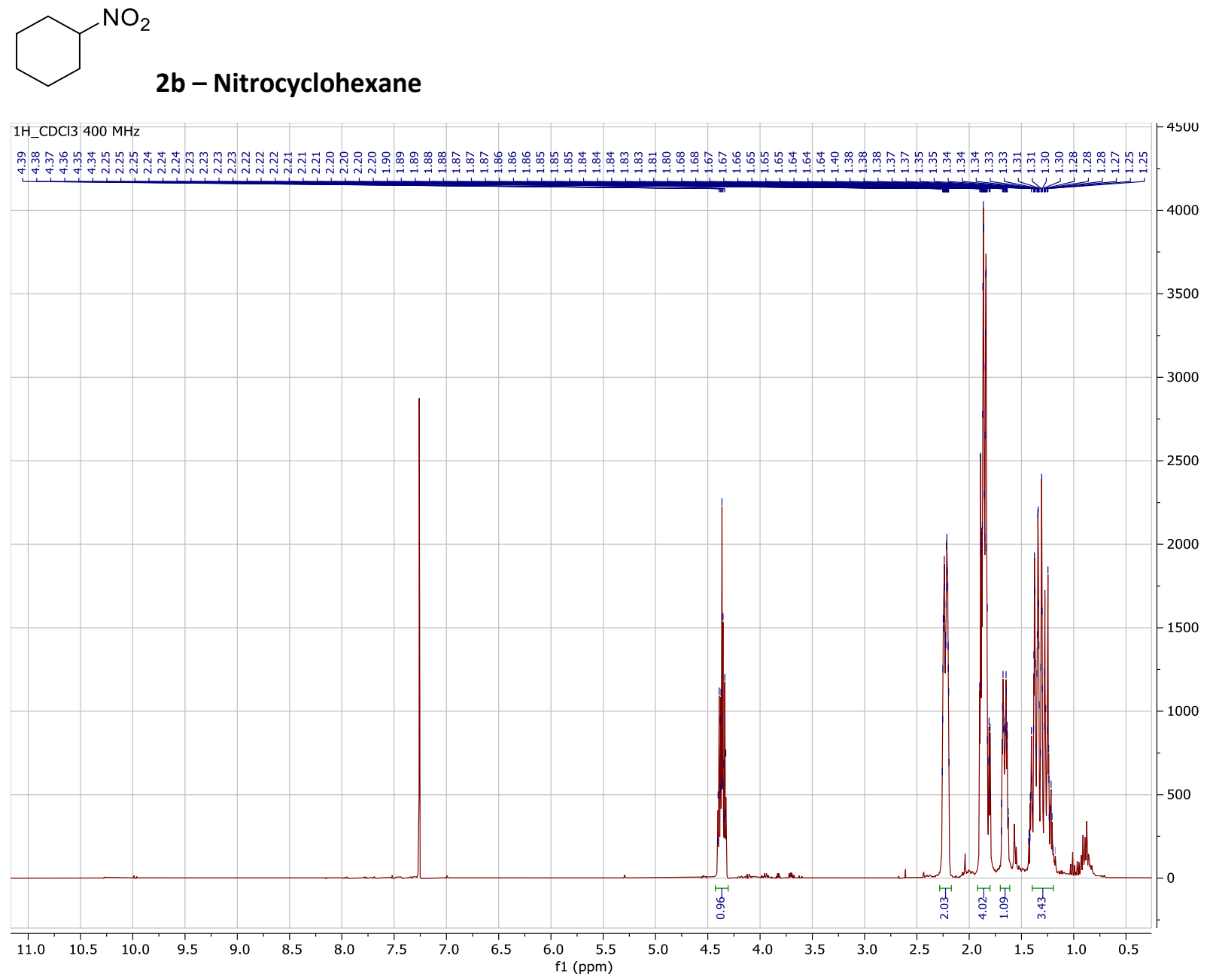


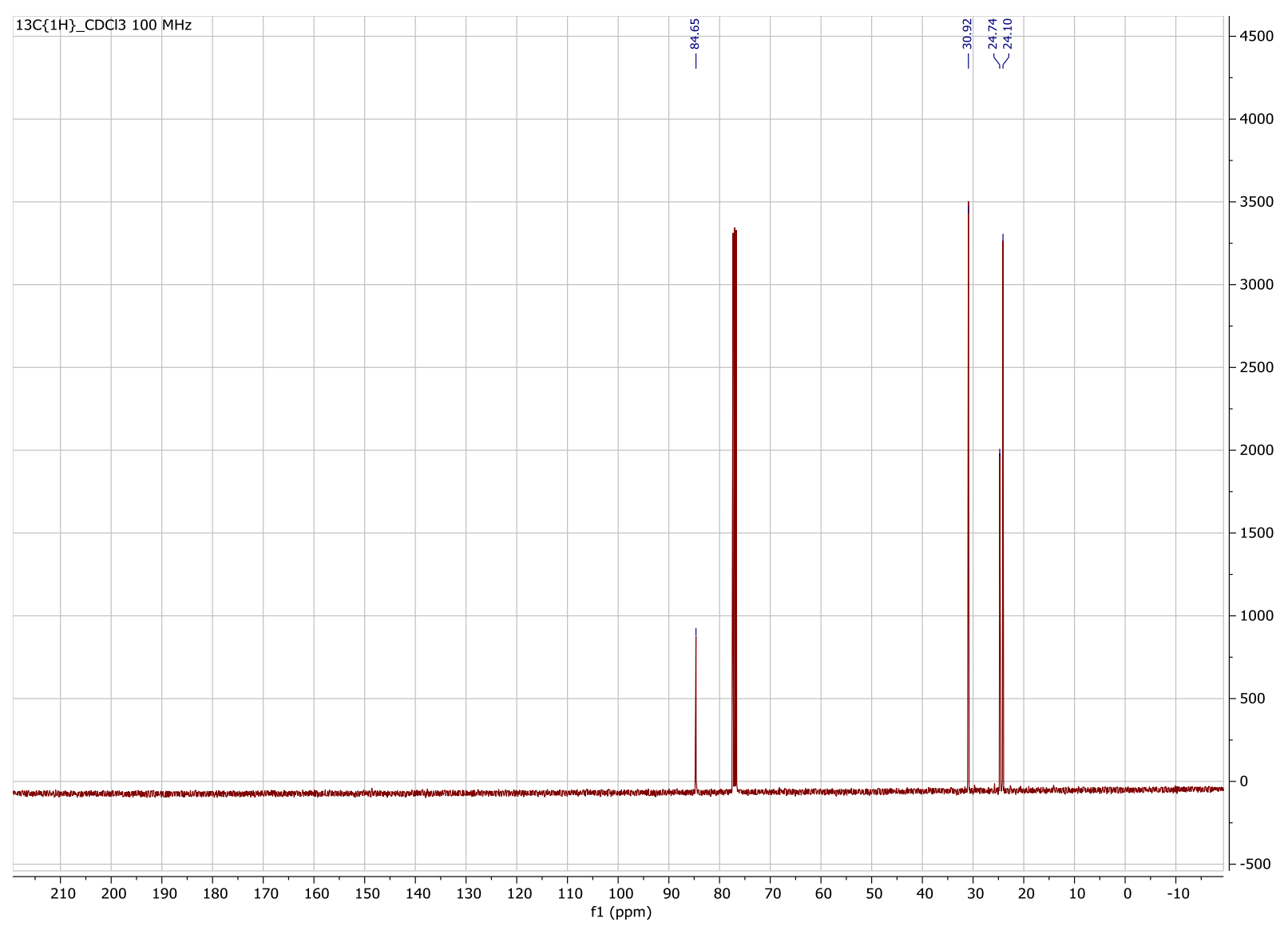


$\sum \mathrm{NO}_{2} 2 \mathrm{c}$-Nitroadamantane

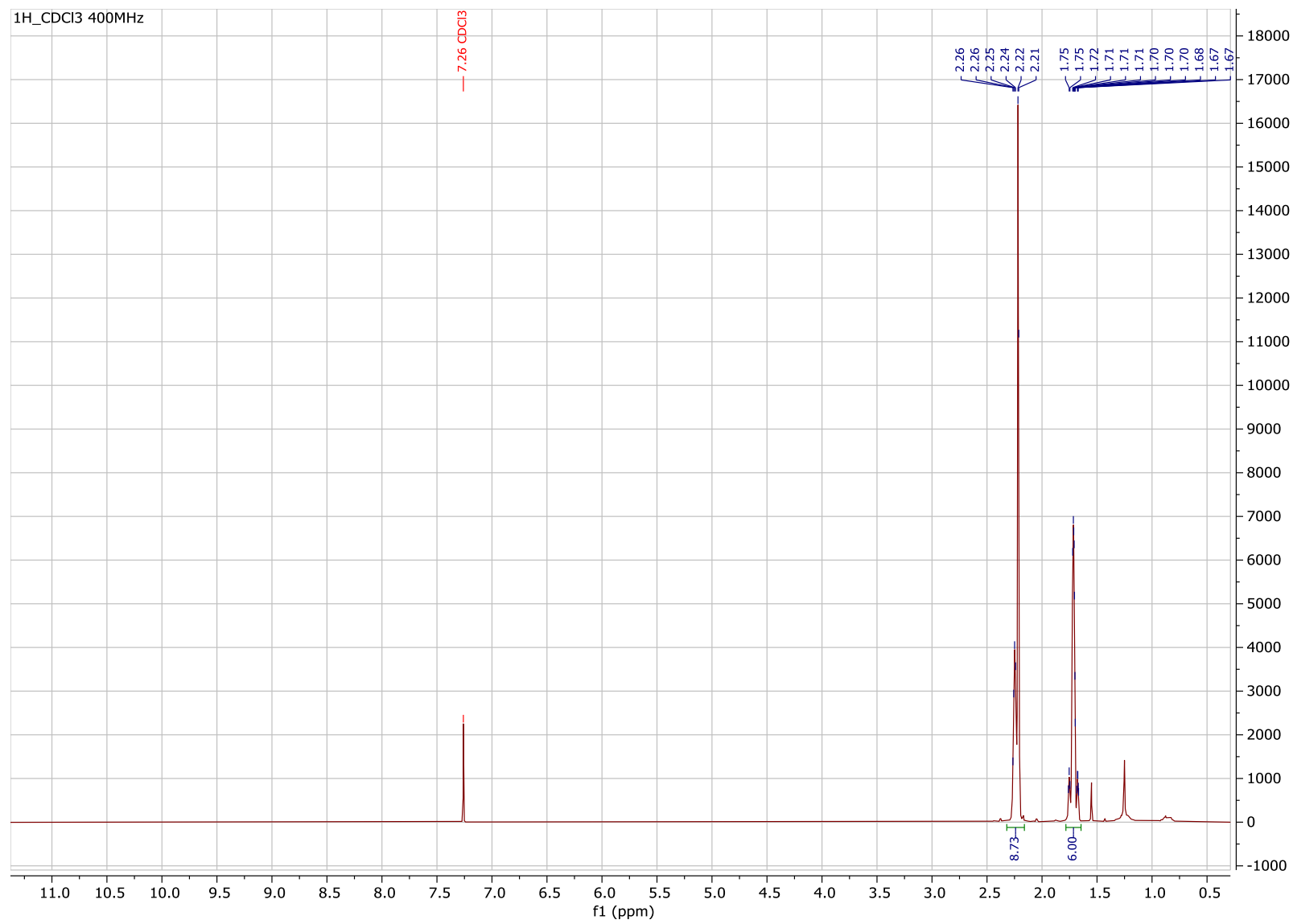




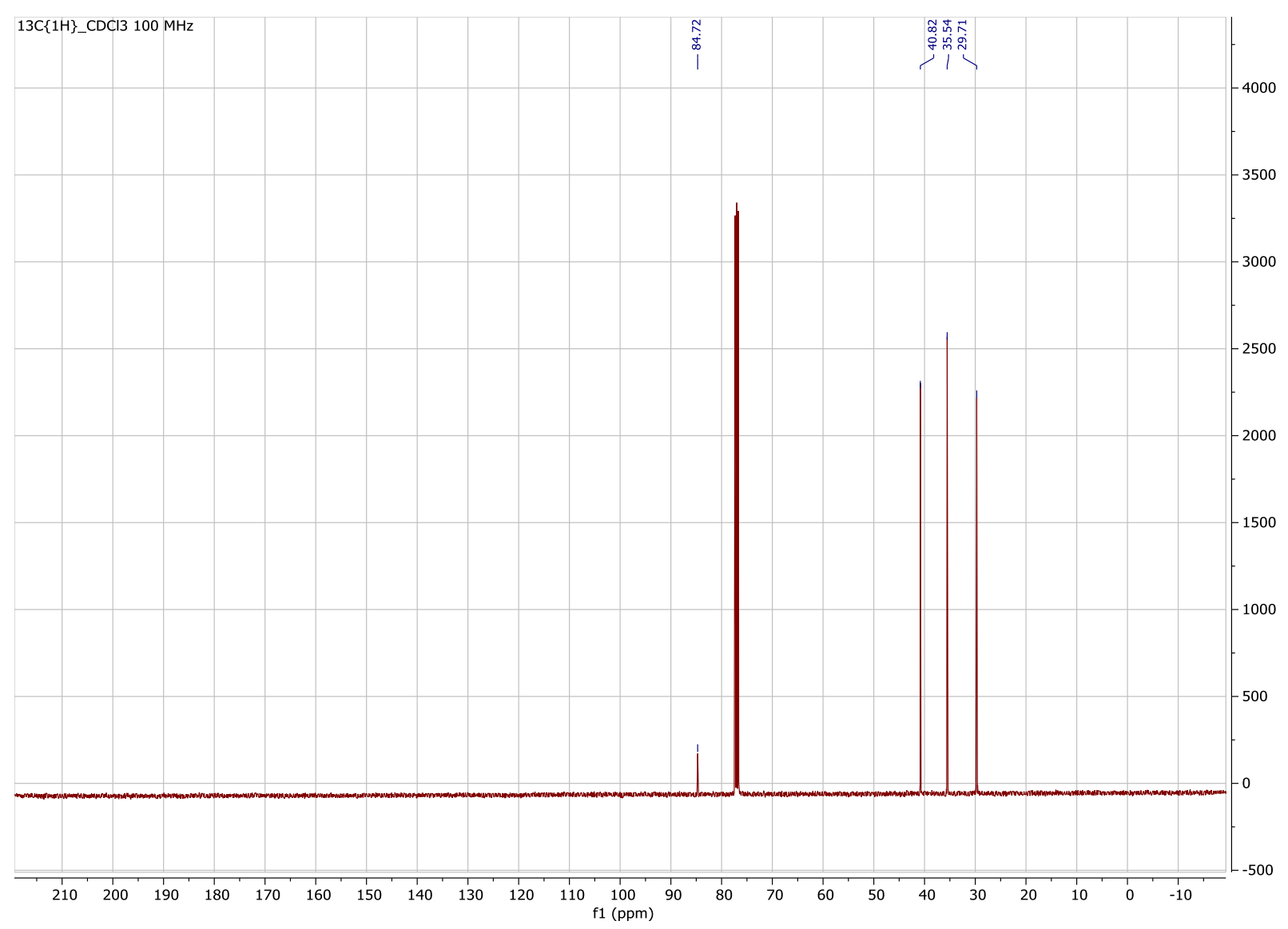



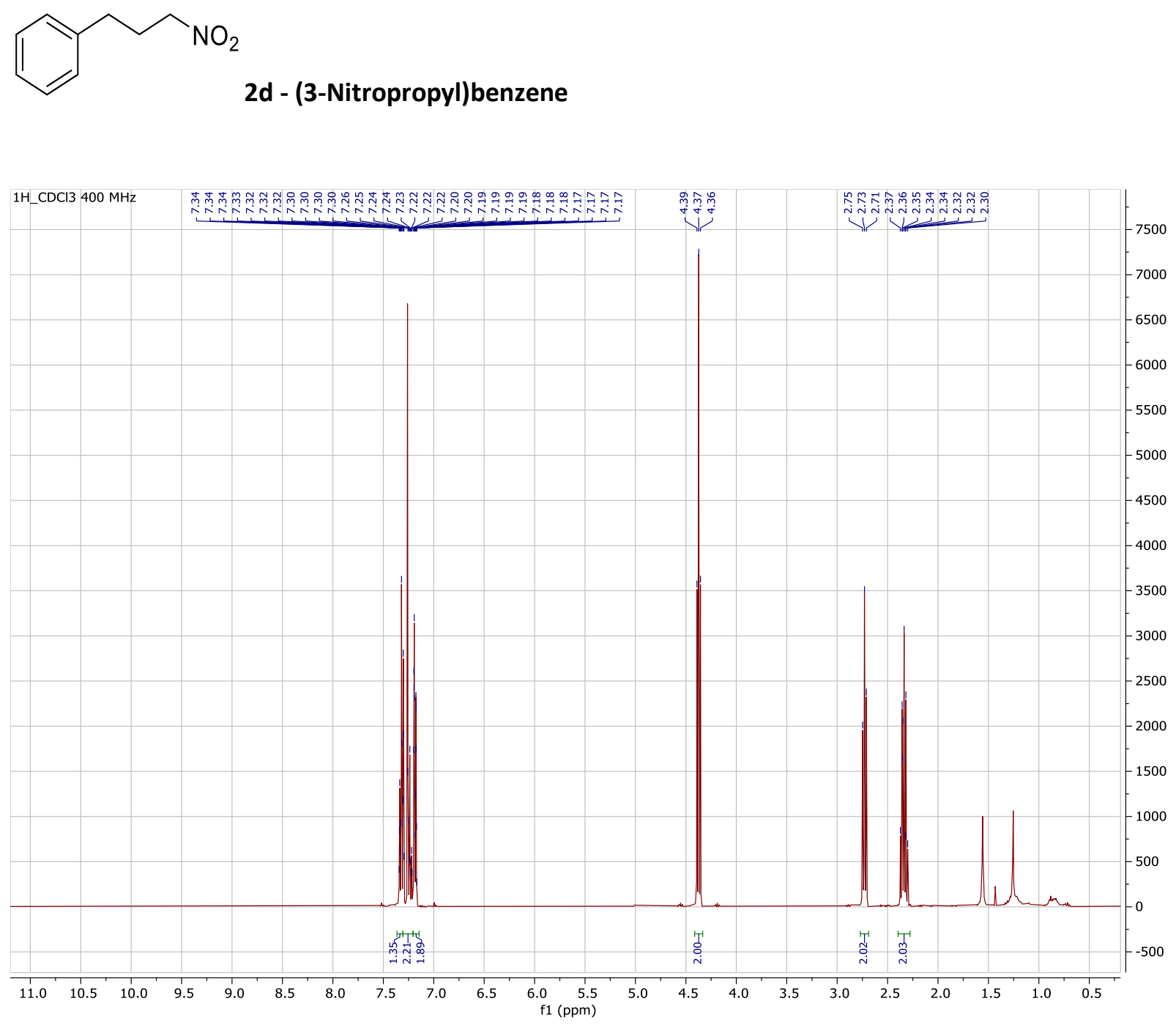


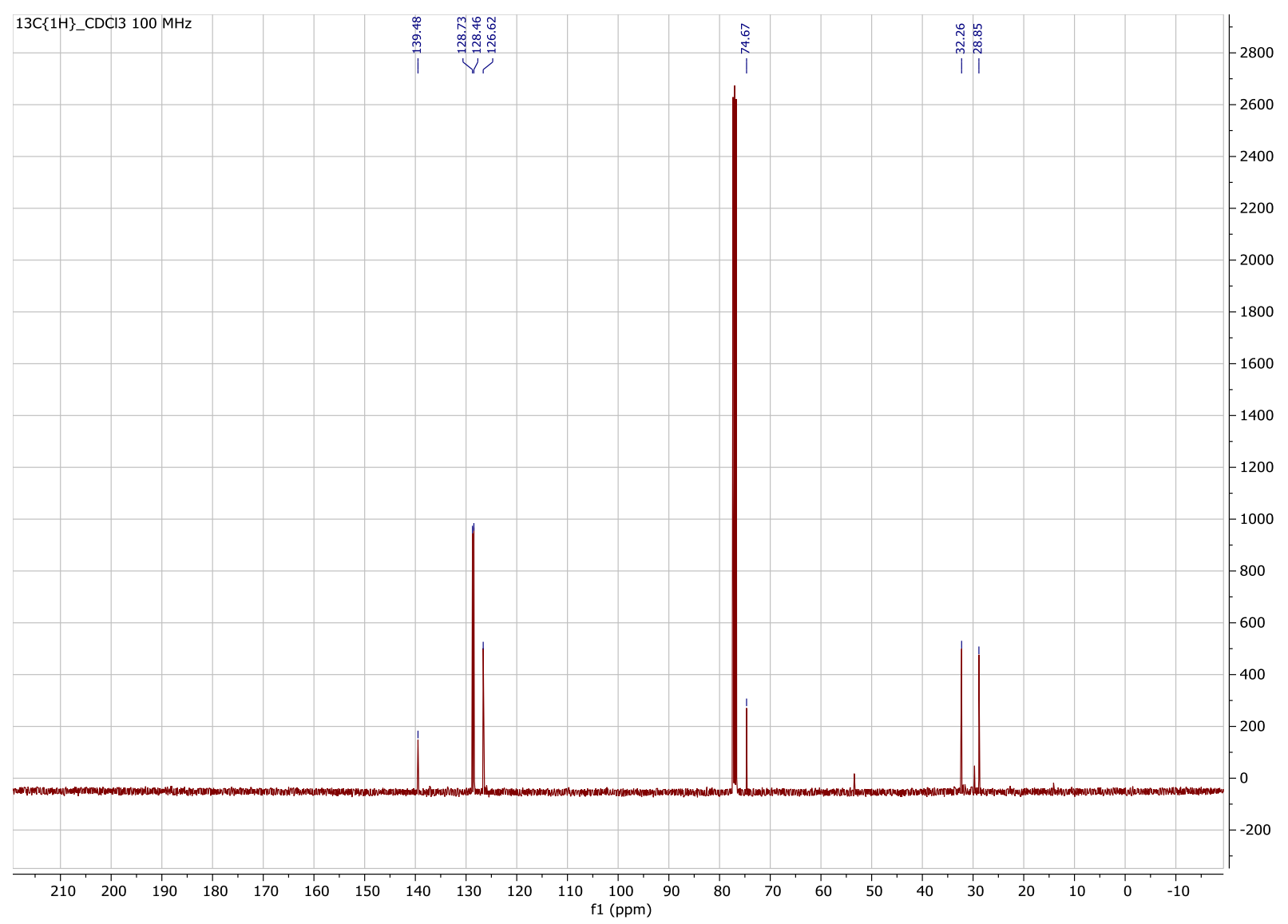


$\mathrm{NO}_{2}$

2e - 1-(2-Nitroethyl)-4-(Trifluoromethyl)benzene

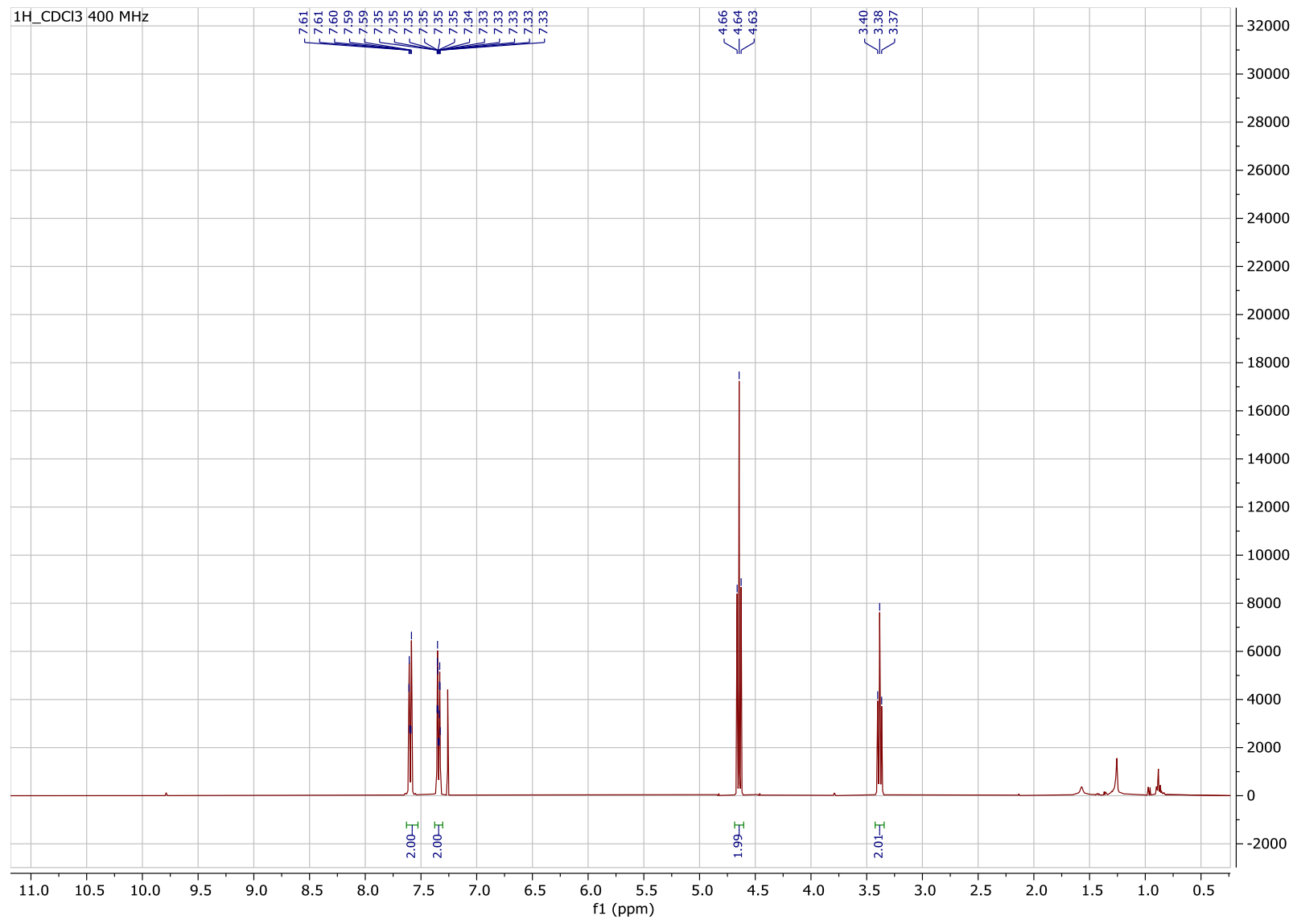




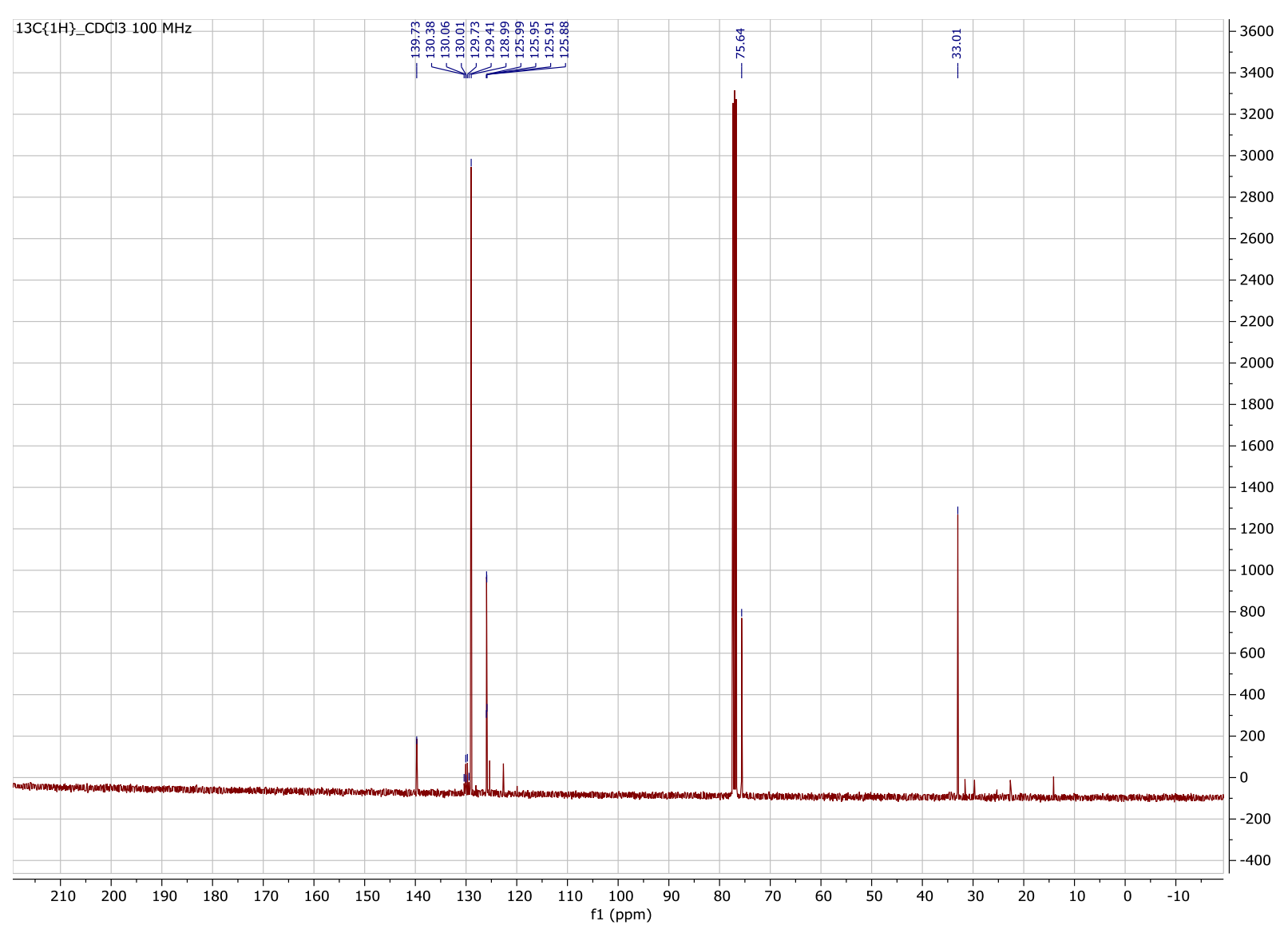


<smiles>O=[N+]([O-])CCc1ccc(Cl)cc1</smiles>

\section{2f - 1-(2-Nitroethyl)-4-Chlorobenzene}

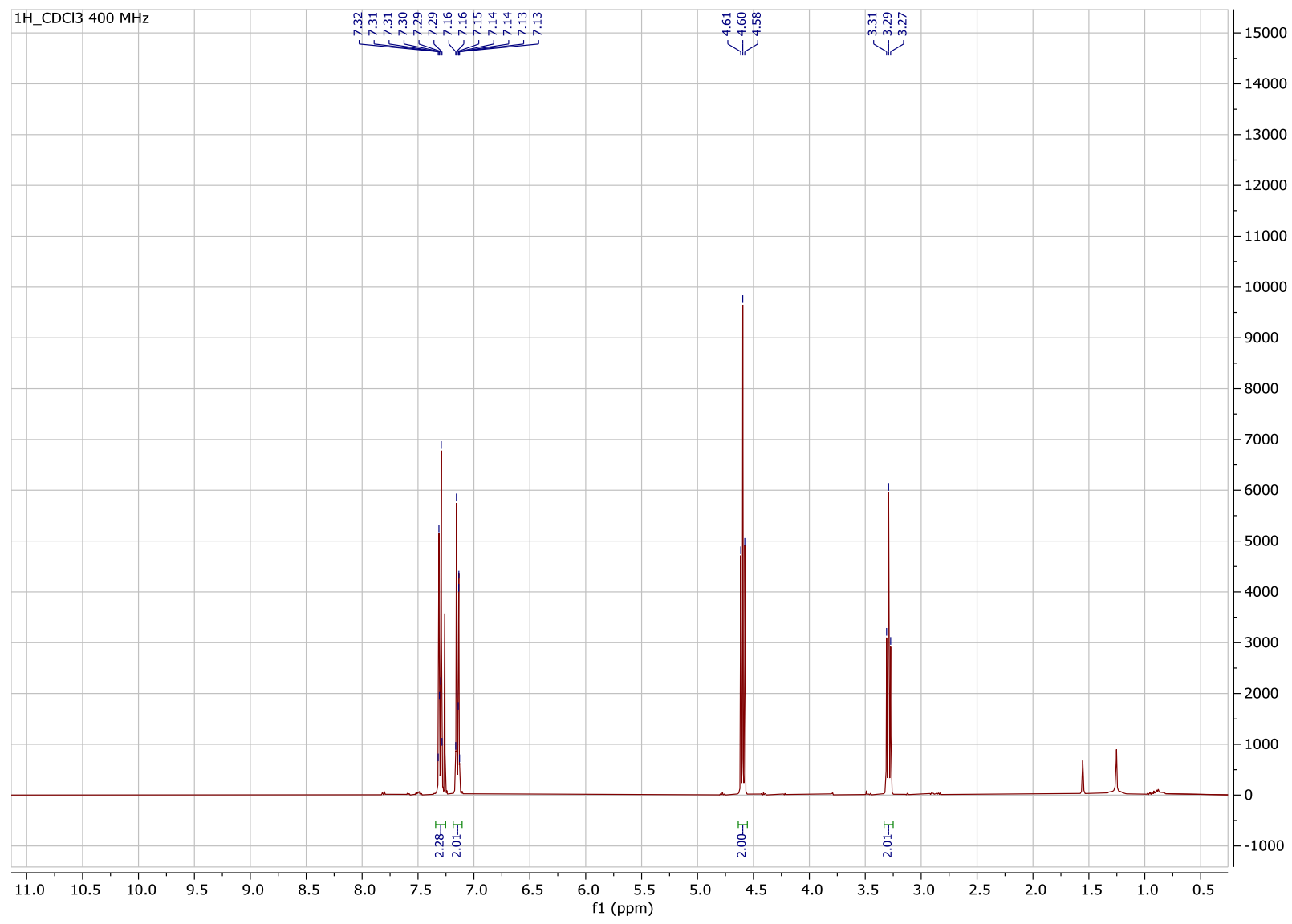




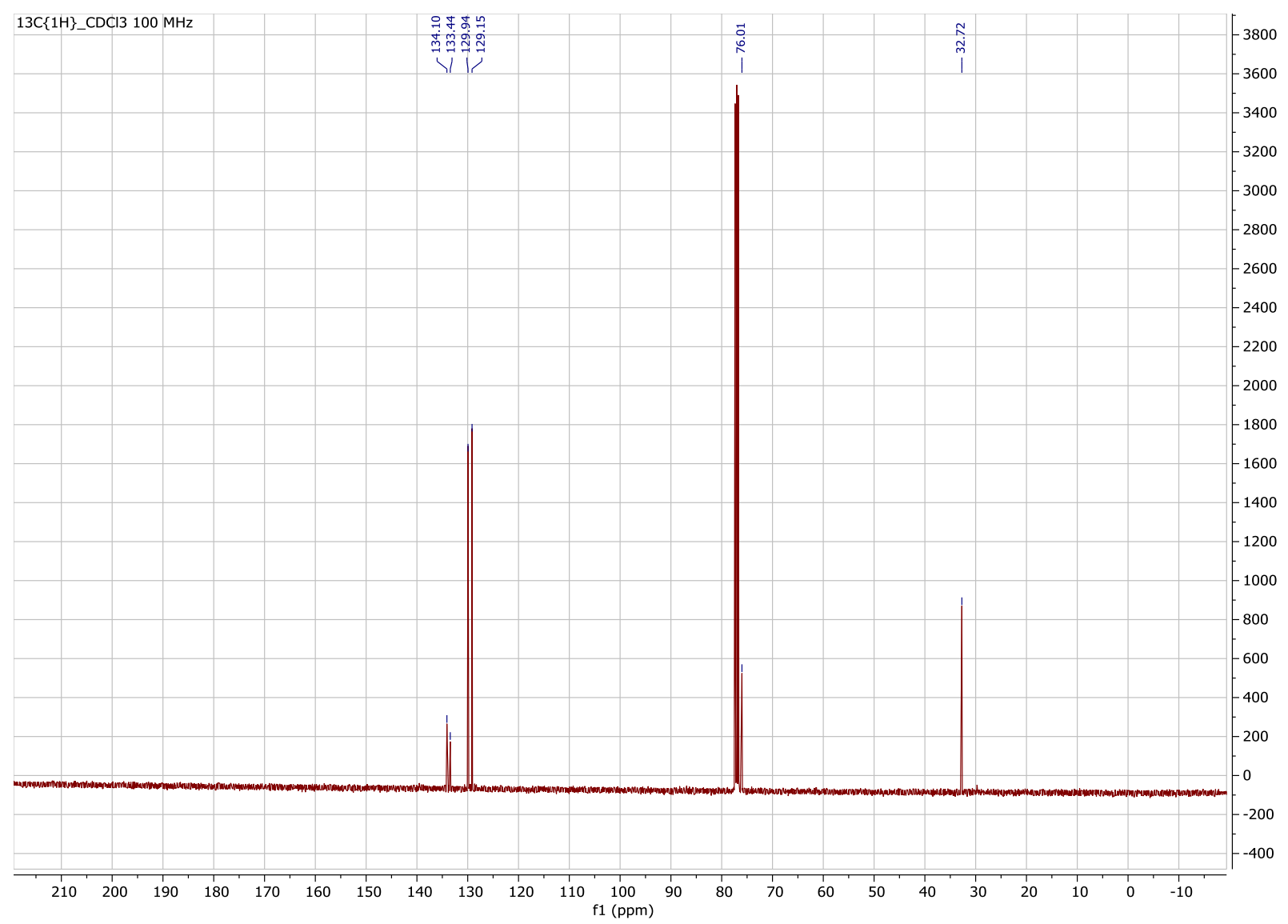




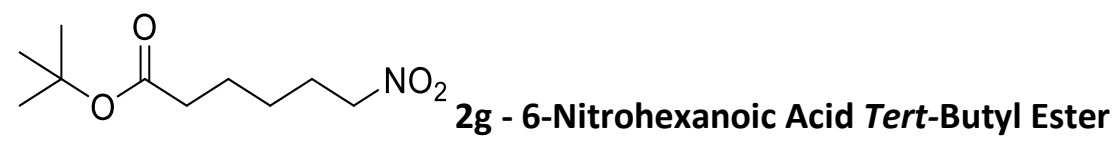

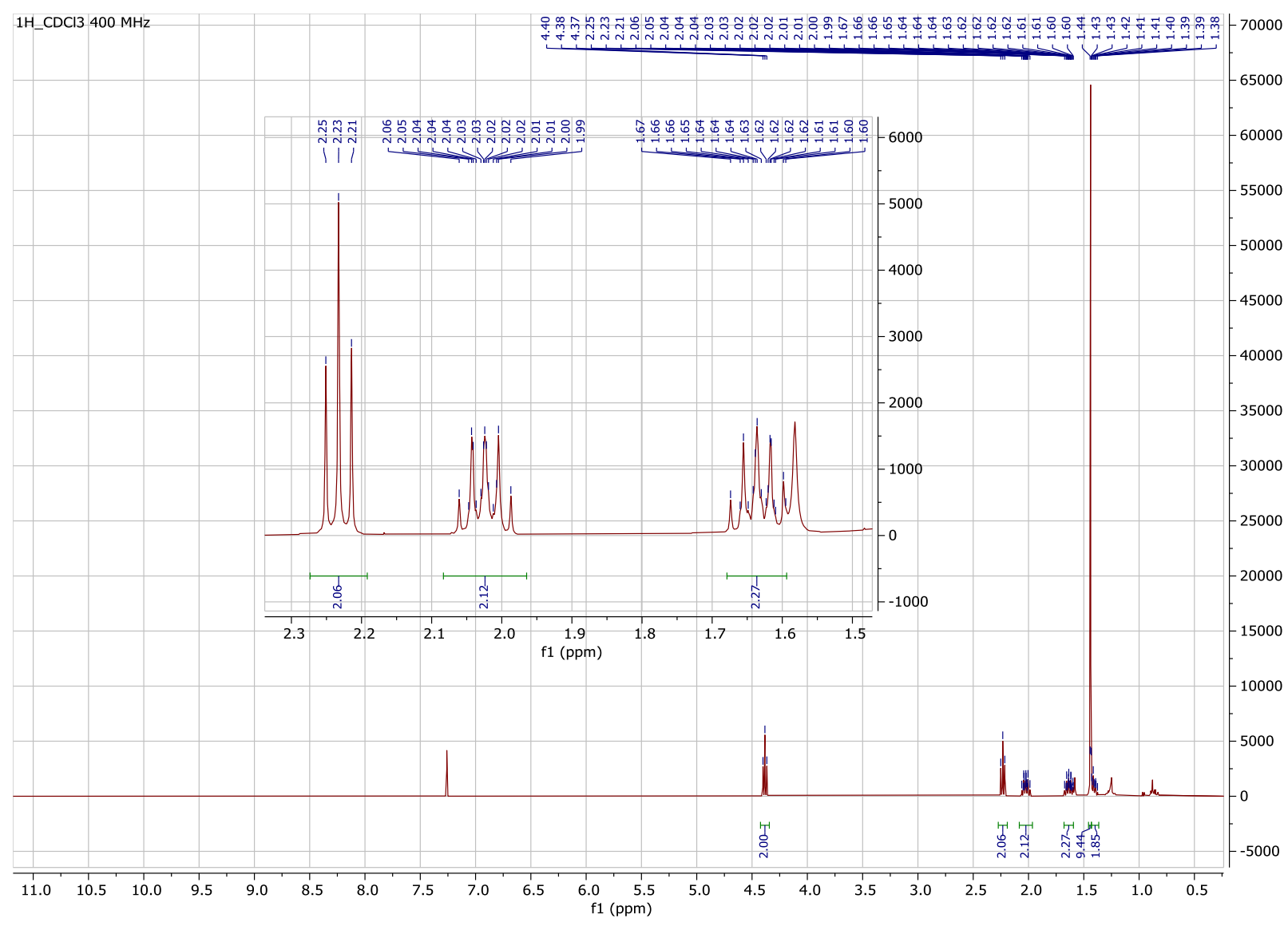




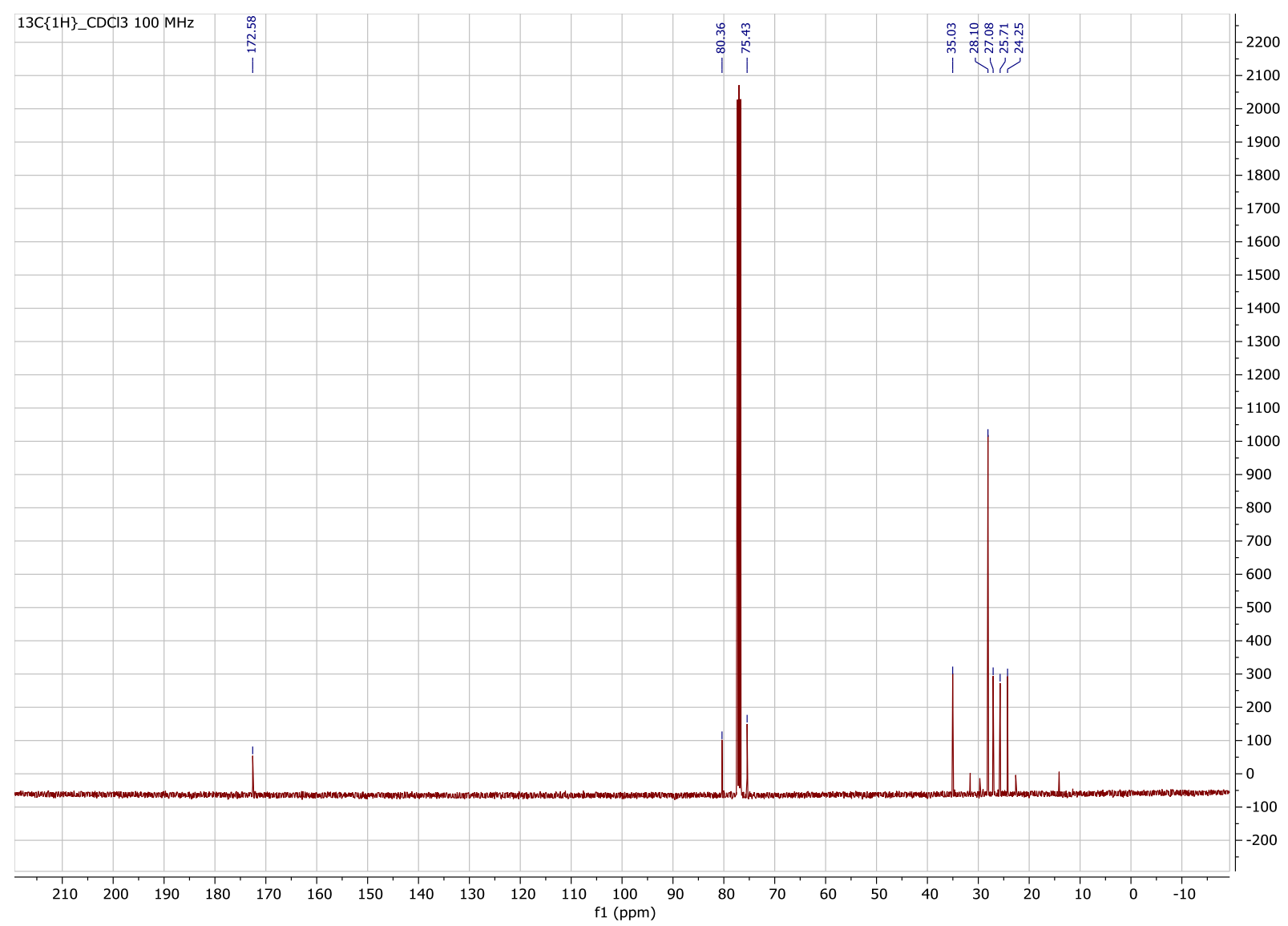






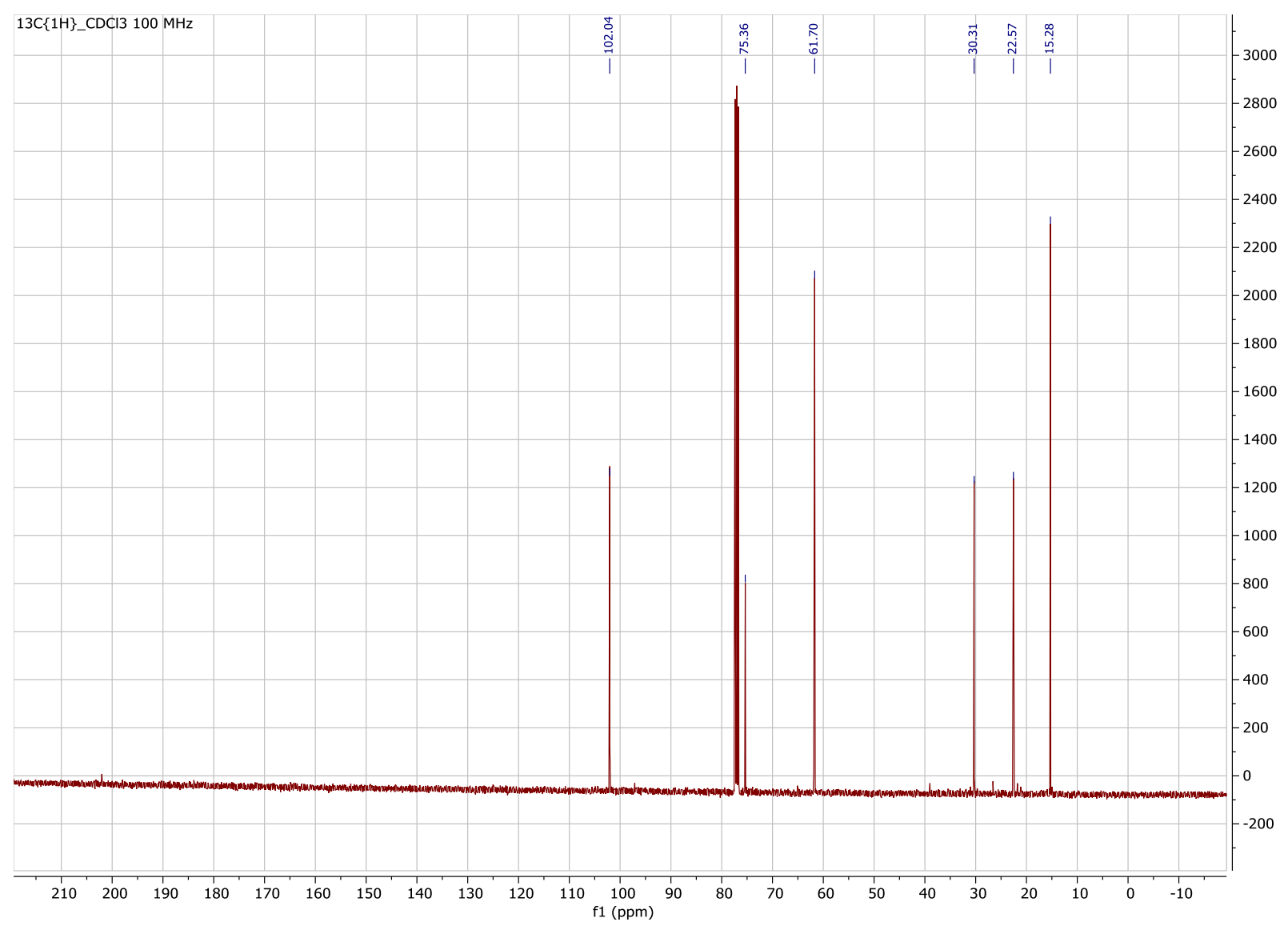


$\mathrm{NO}_{2 \mathrm{i} \text { - Tert-Butyl Nitrophenylpropanoate }}$

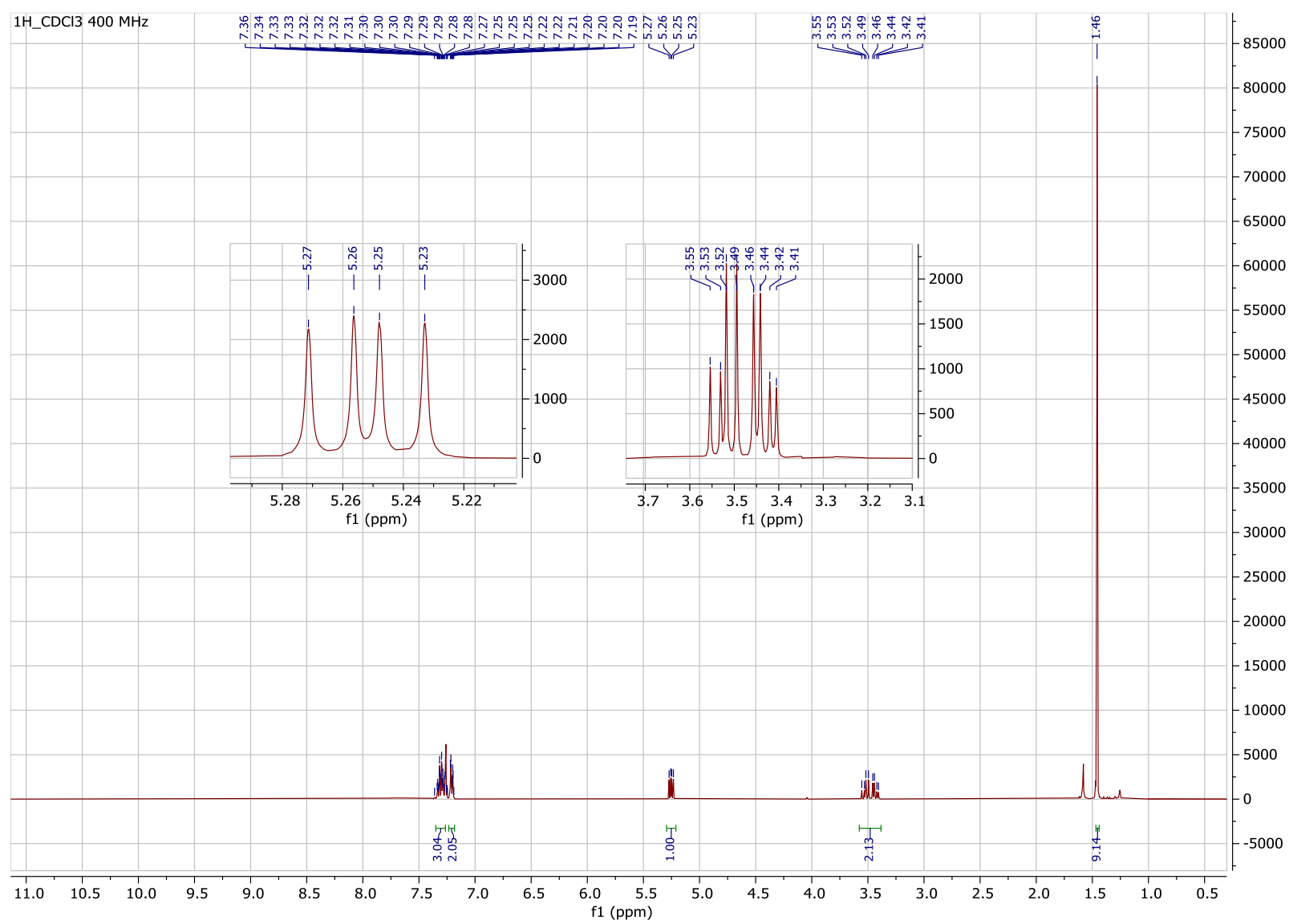




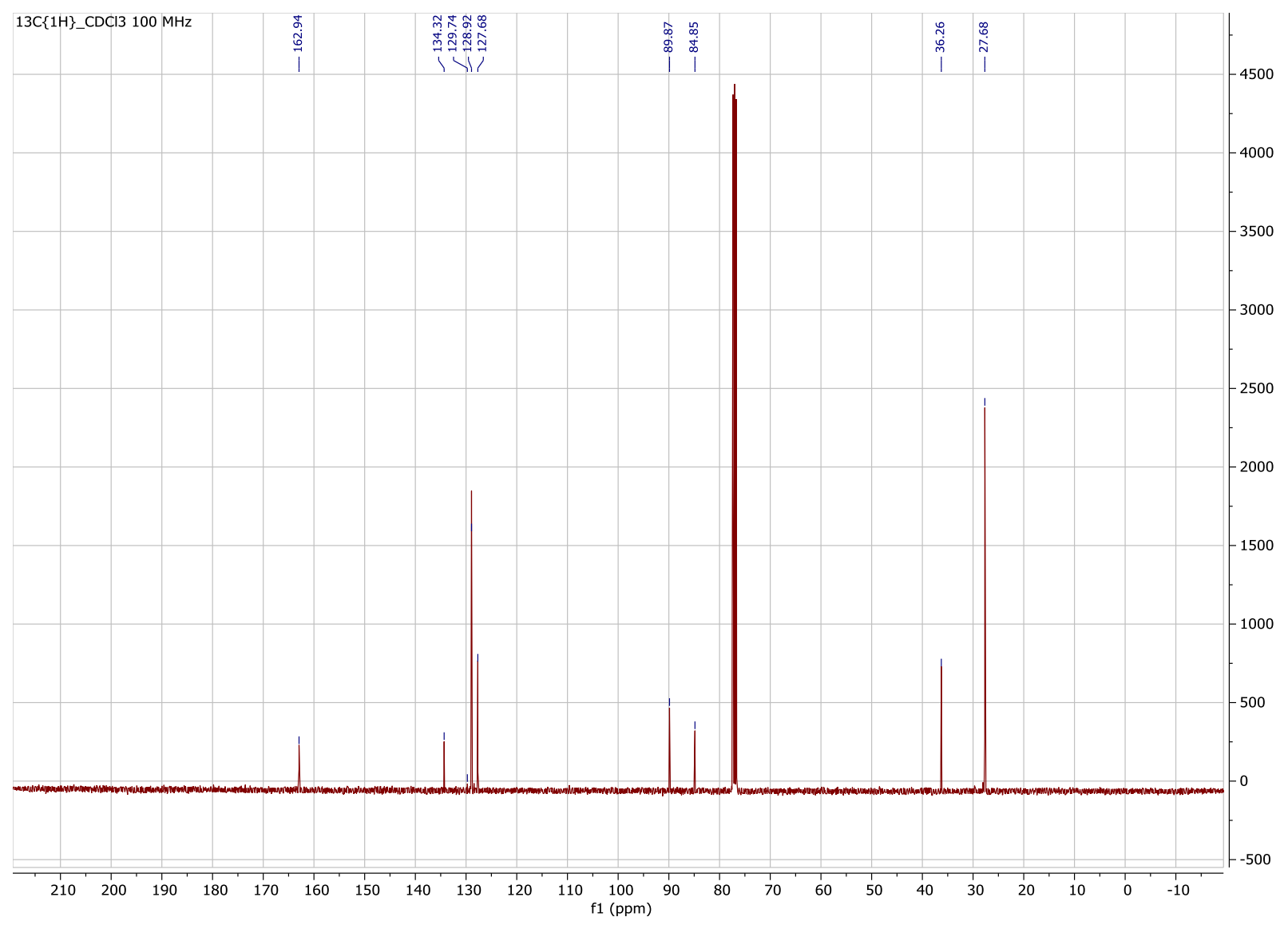


(NO

2j - Trans-4-Nitrocyclohexanol

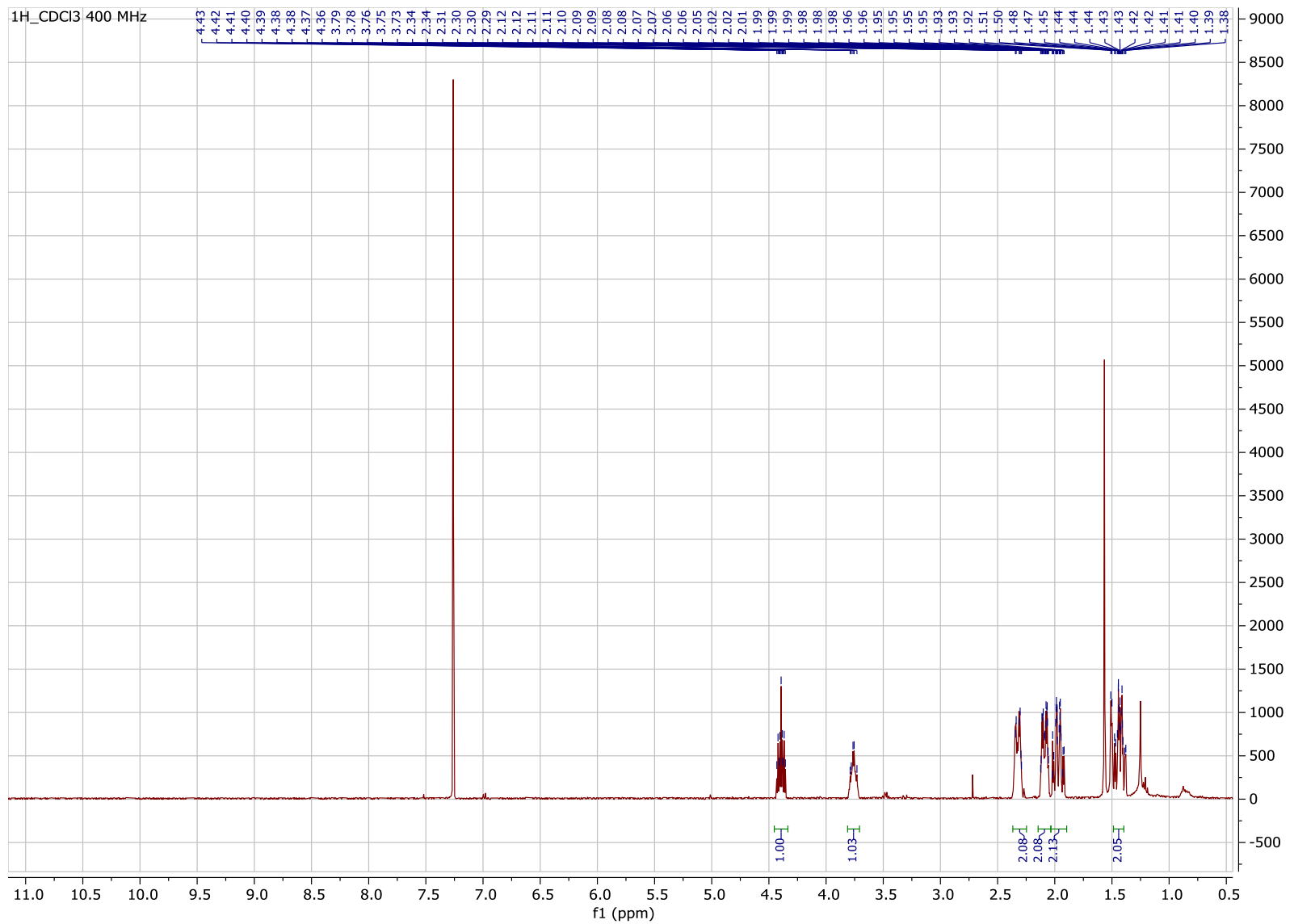




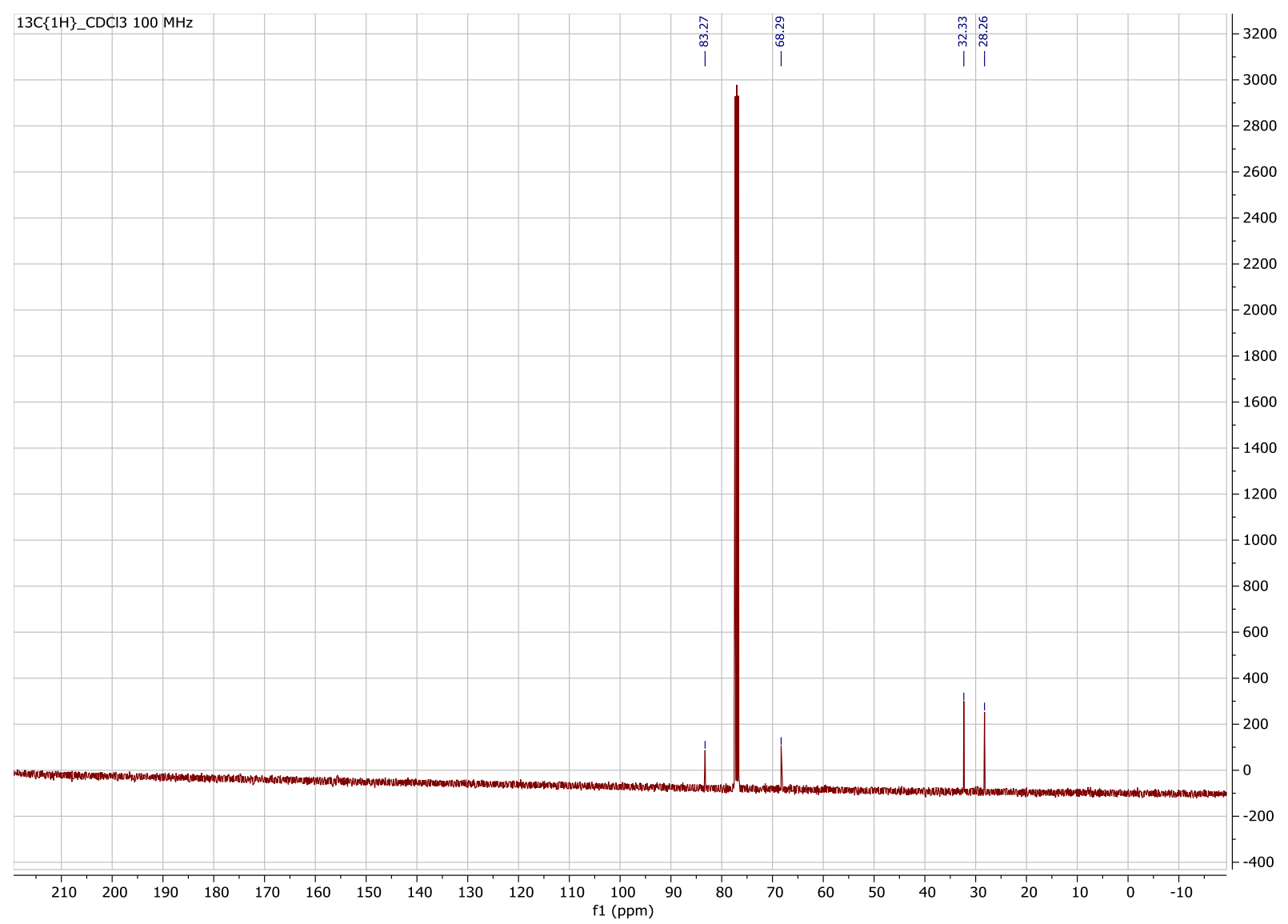


$\mathrm{NO}_{2} 2 \mathrm{k}$ - 1-Nitro-3-Adamantol

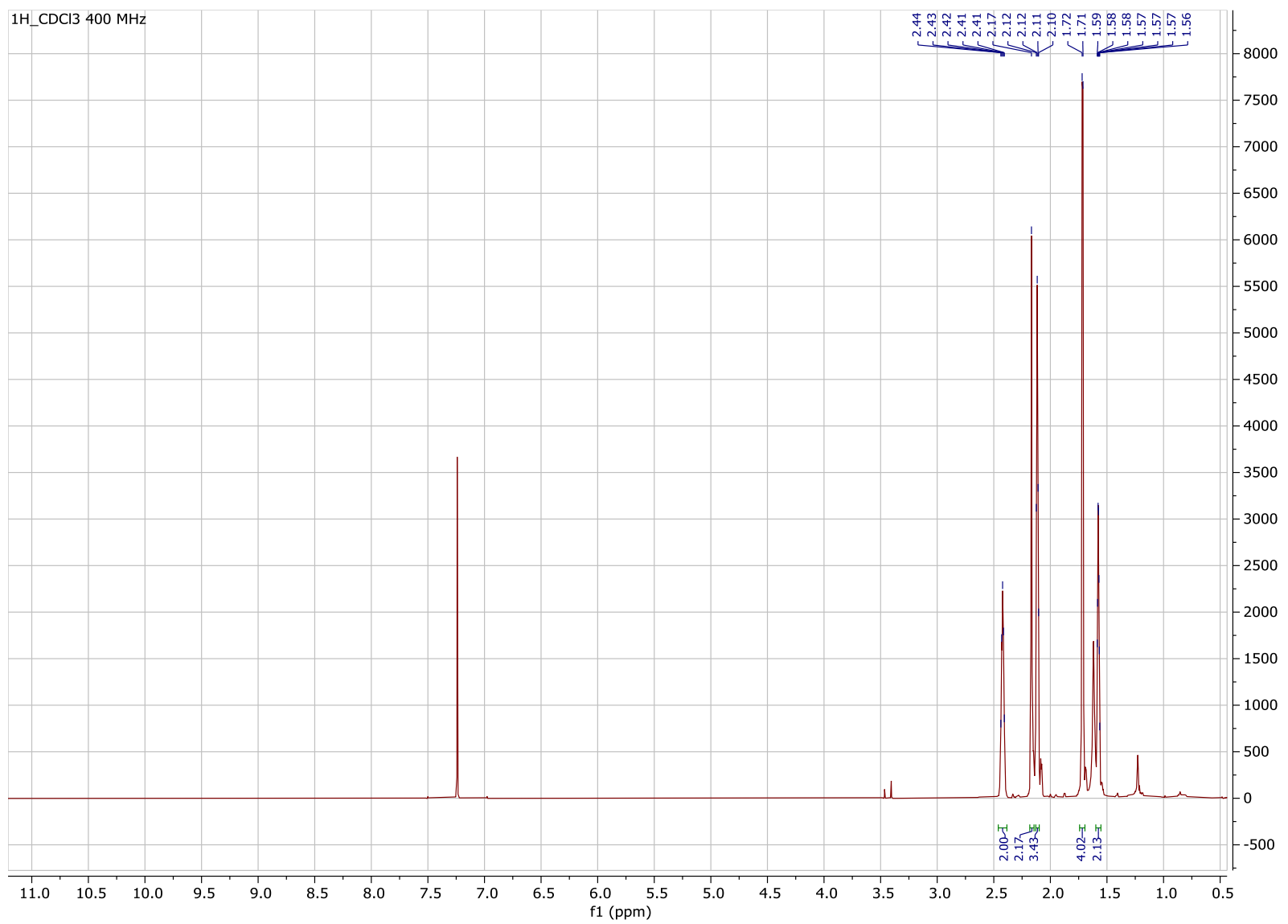




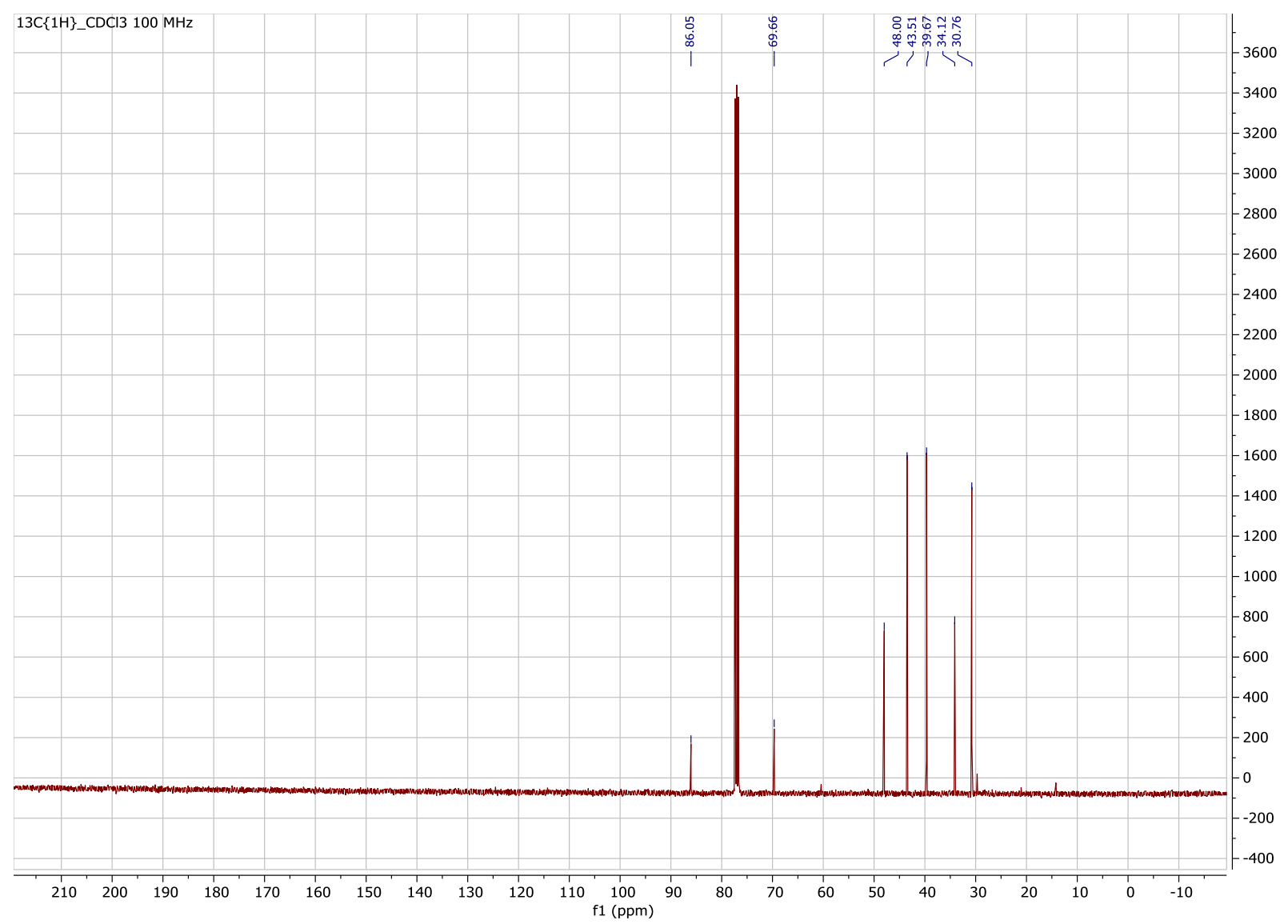



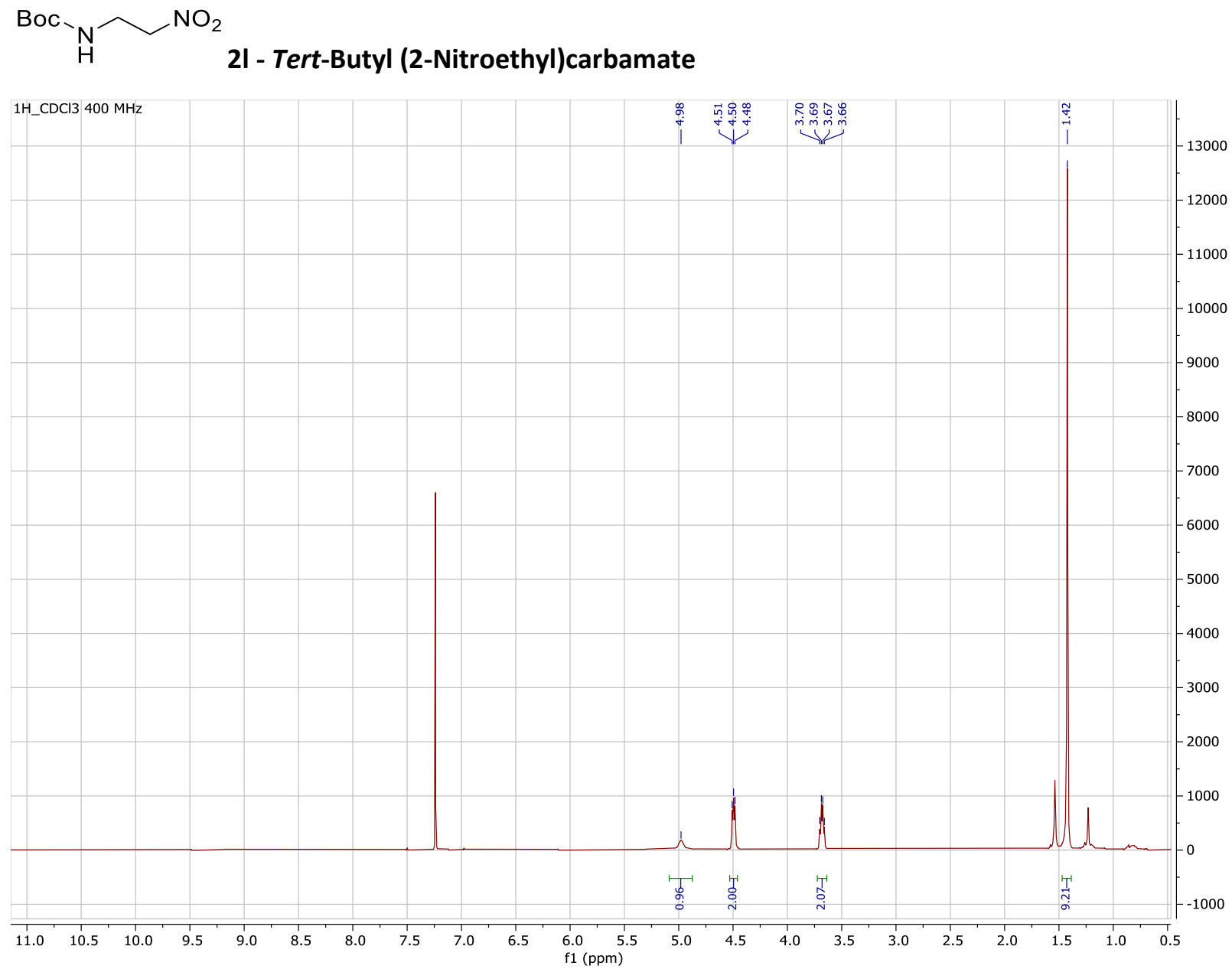


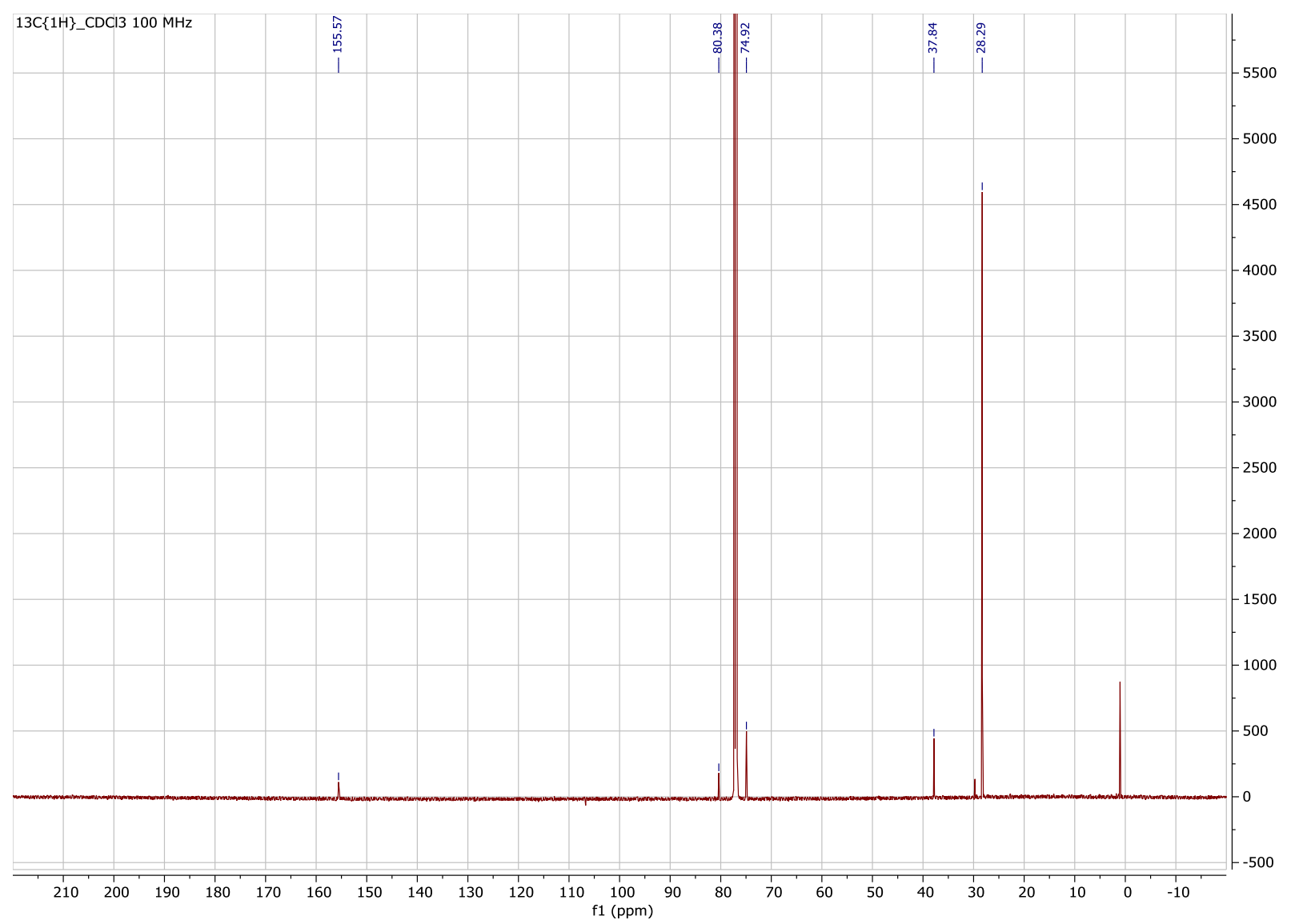


${ }^{\mathrm{O}} \mathrm{Nm}^{\mathrm{NO}_{2}}$ 2-(Nitromethyl)tetrahydrofuran

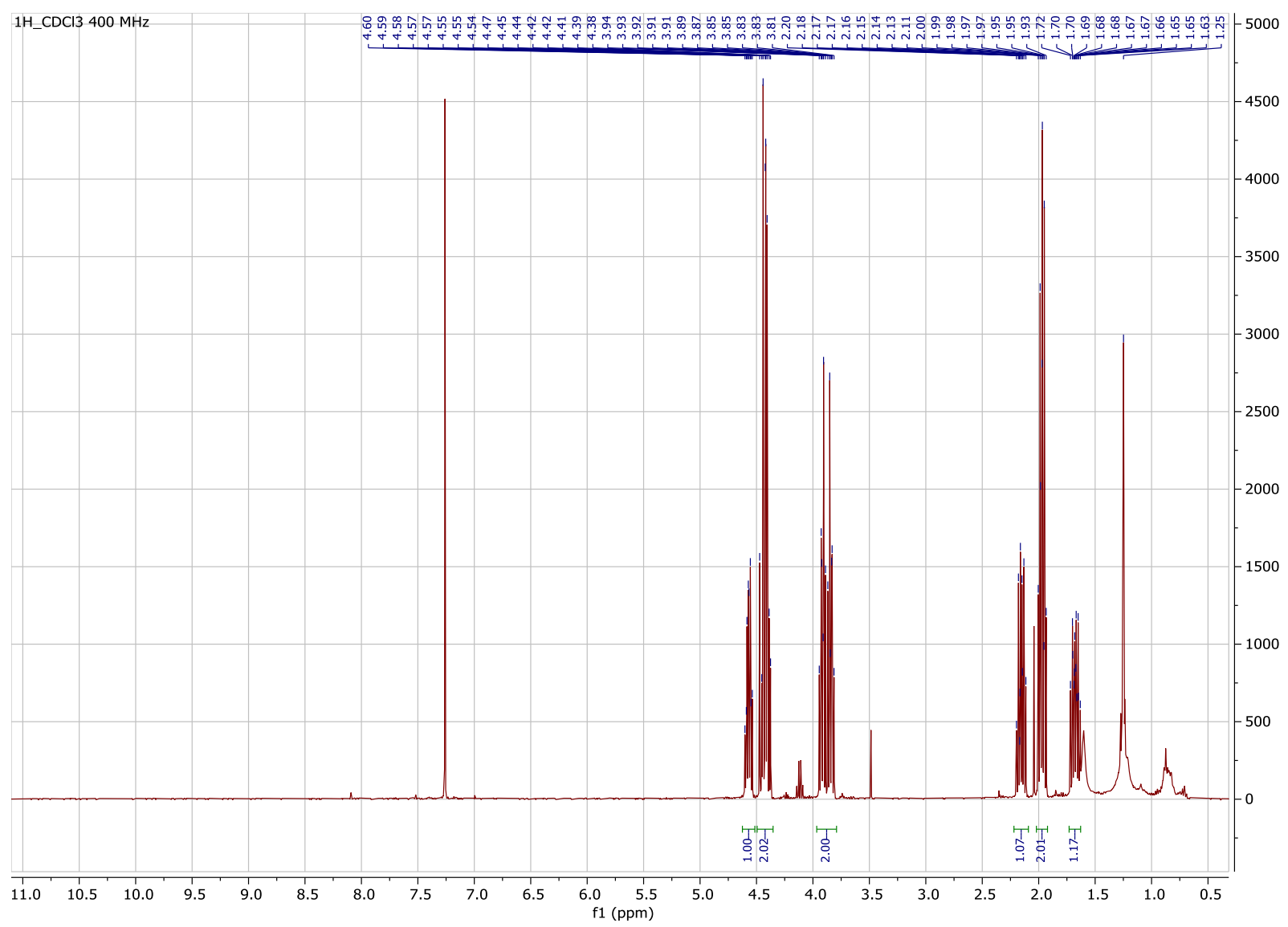




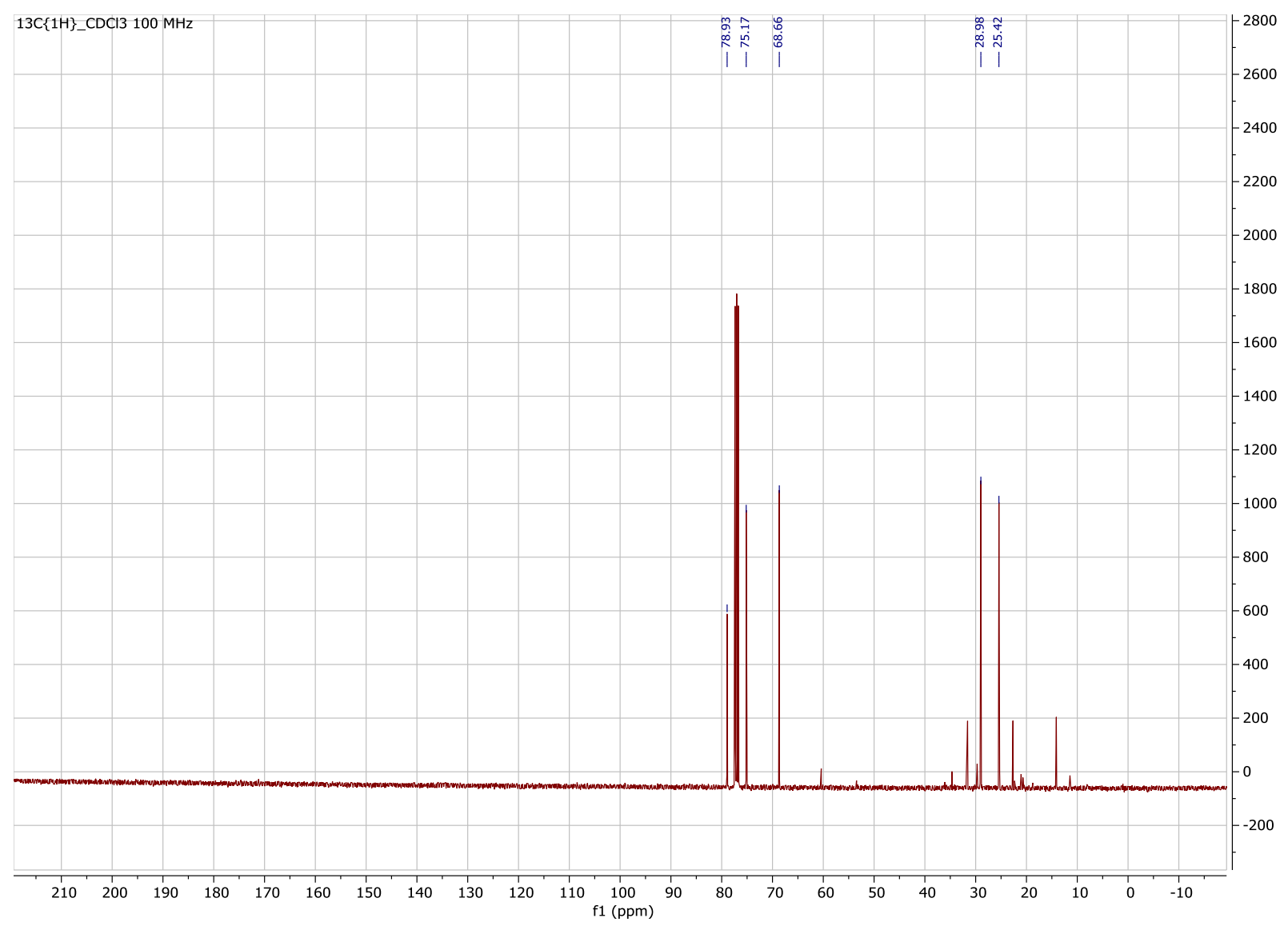




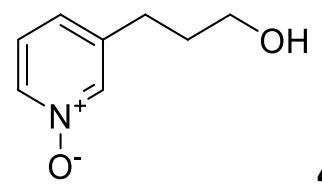

4a - 3-Pyridinylpropanol $\mathrm{N}$-oxide

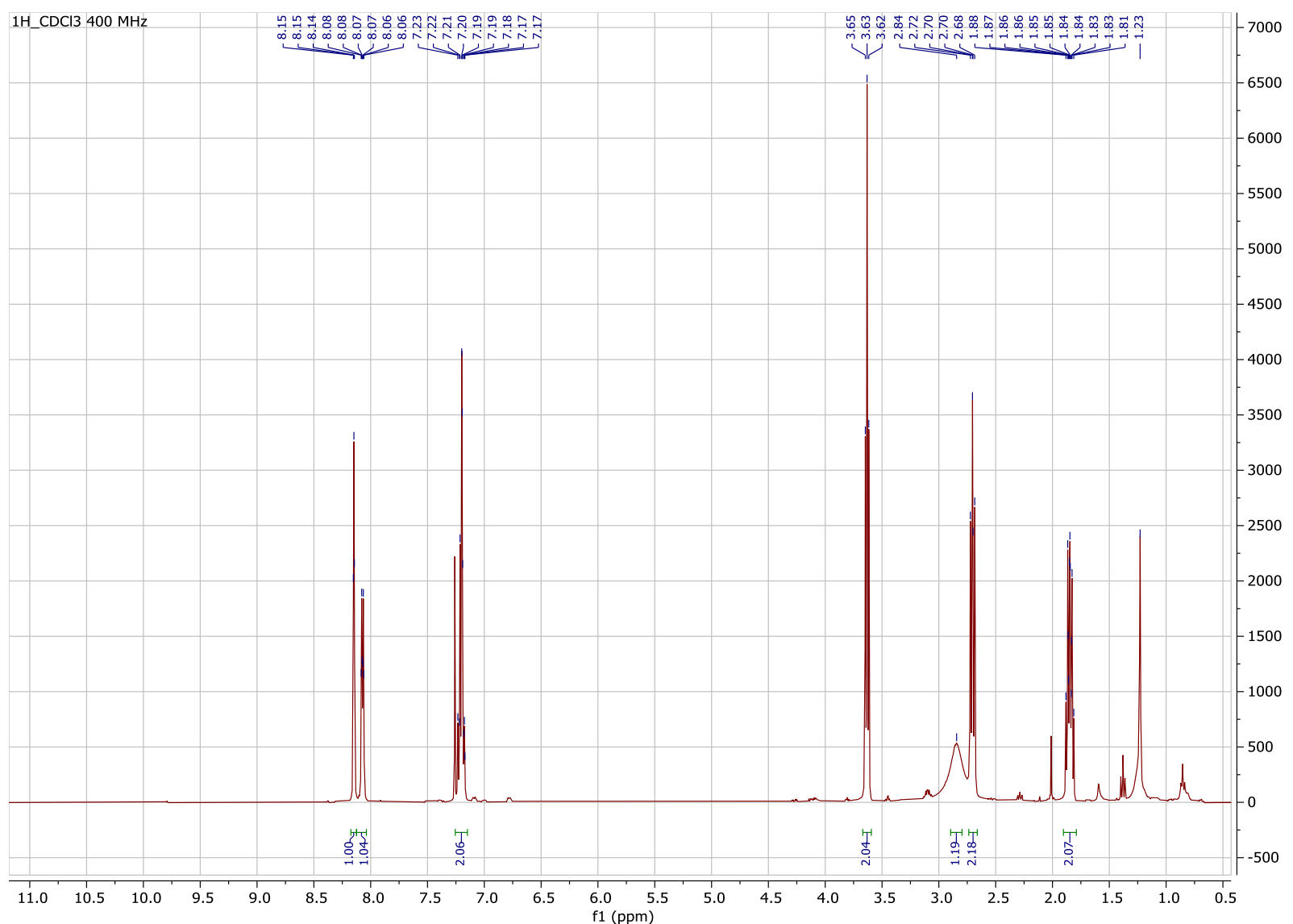




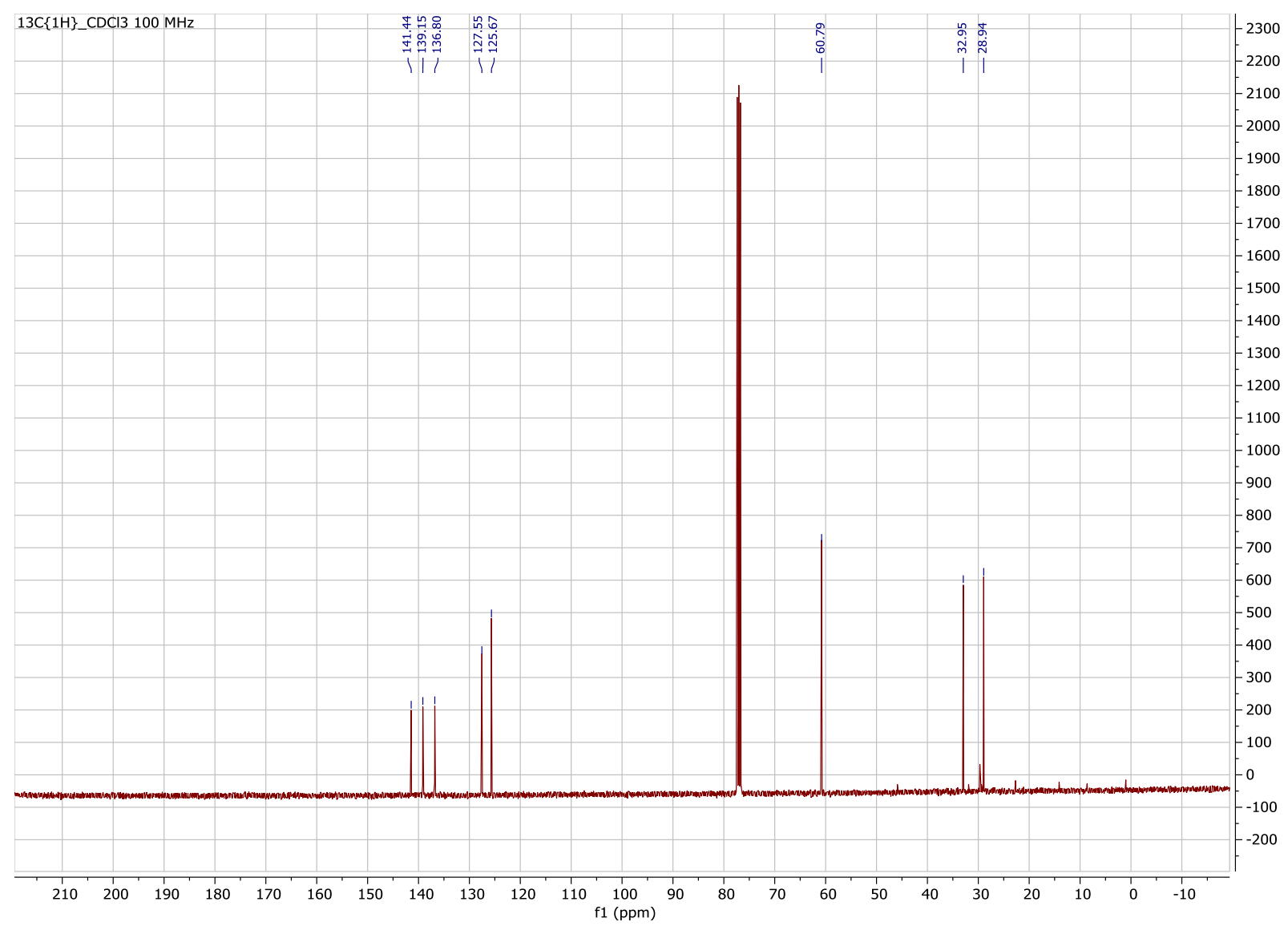



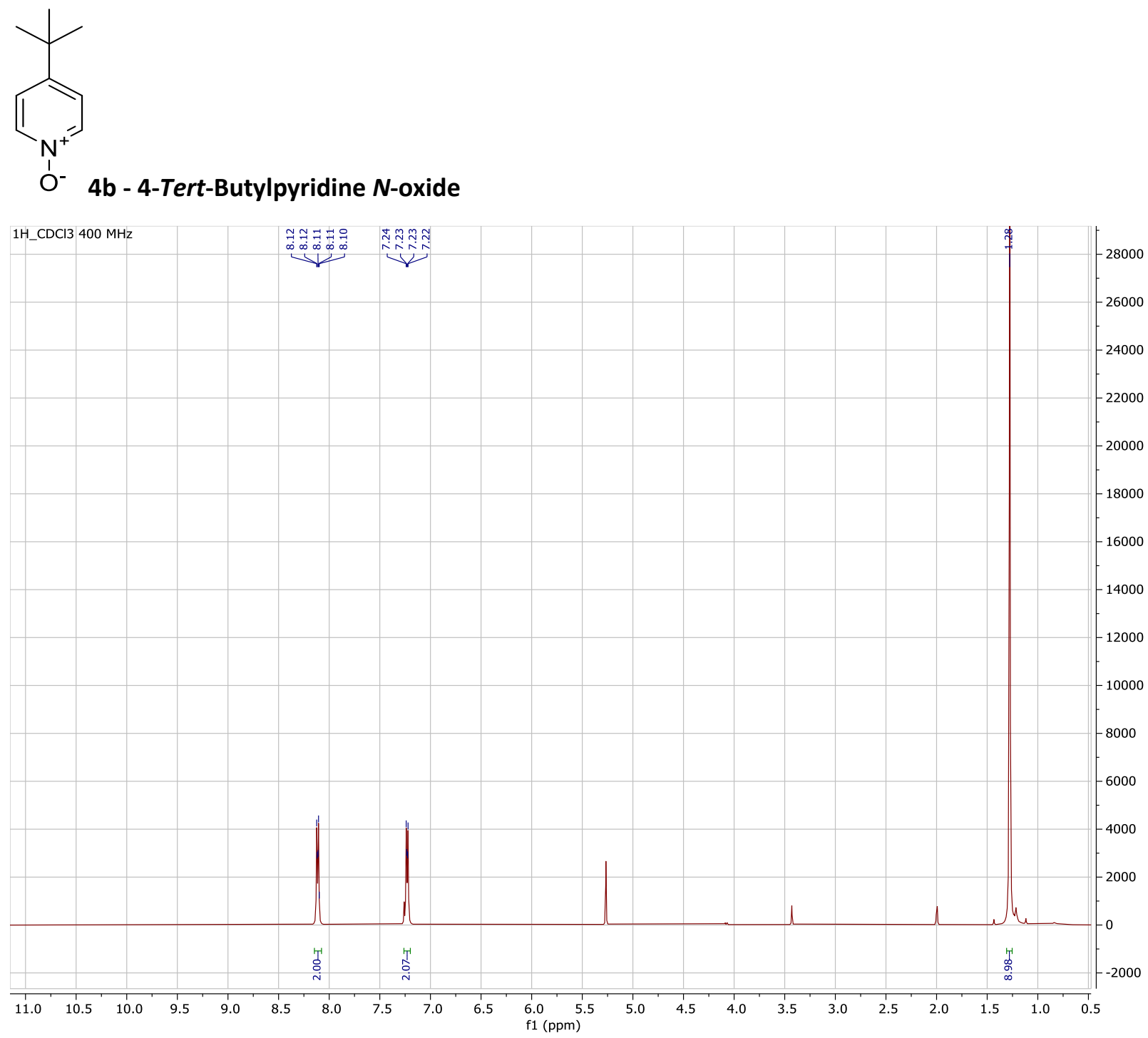


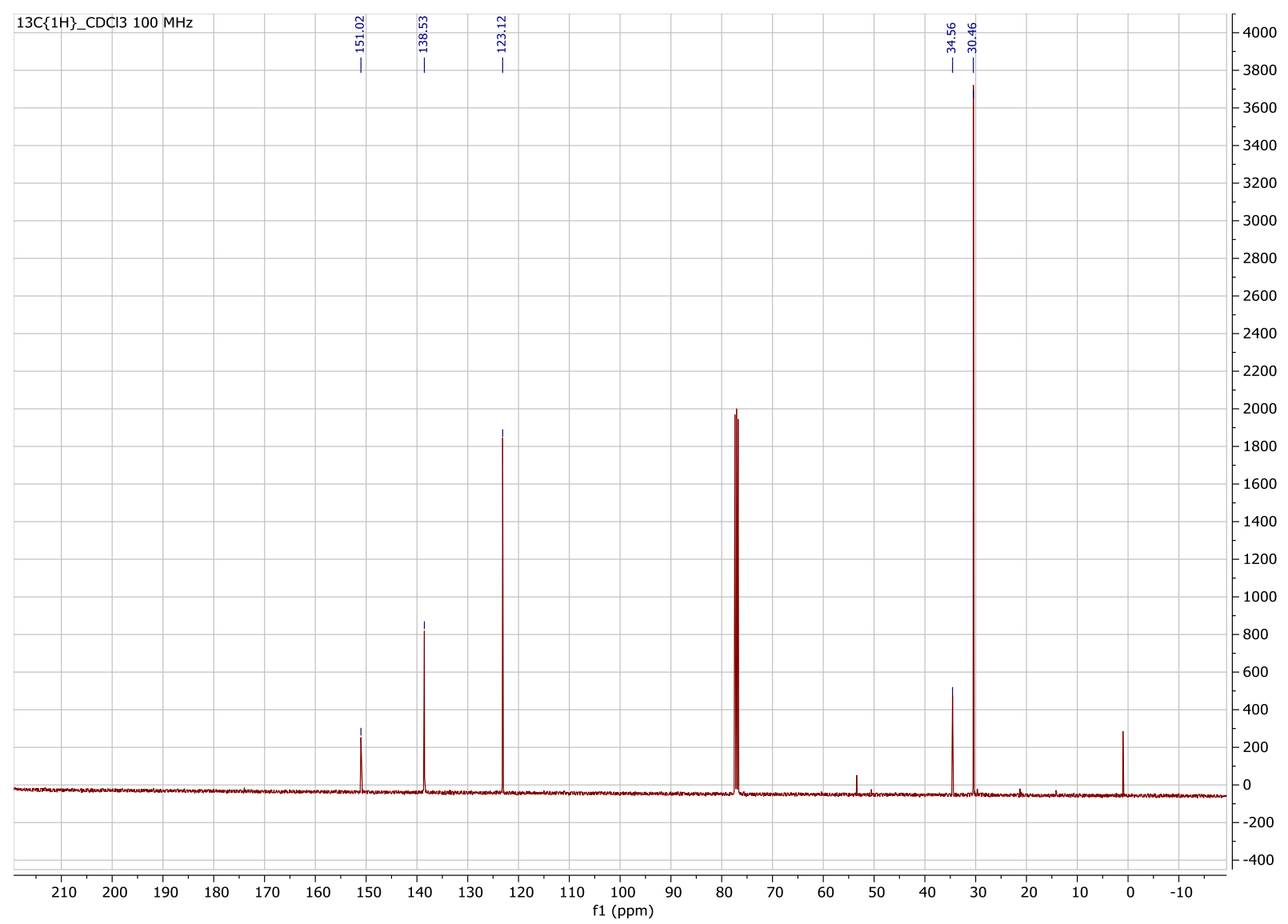


-

1H_CDC13 400 MHz $\quad$ t
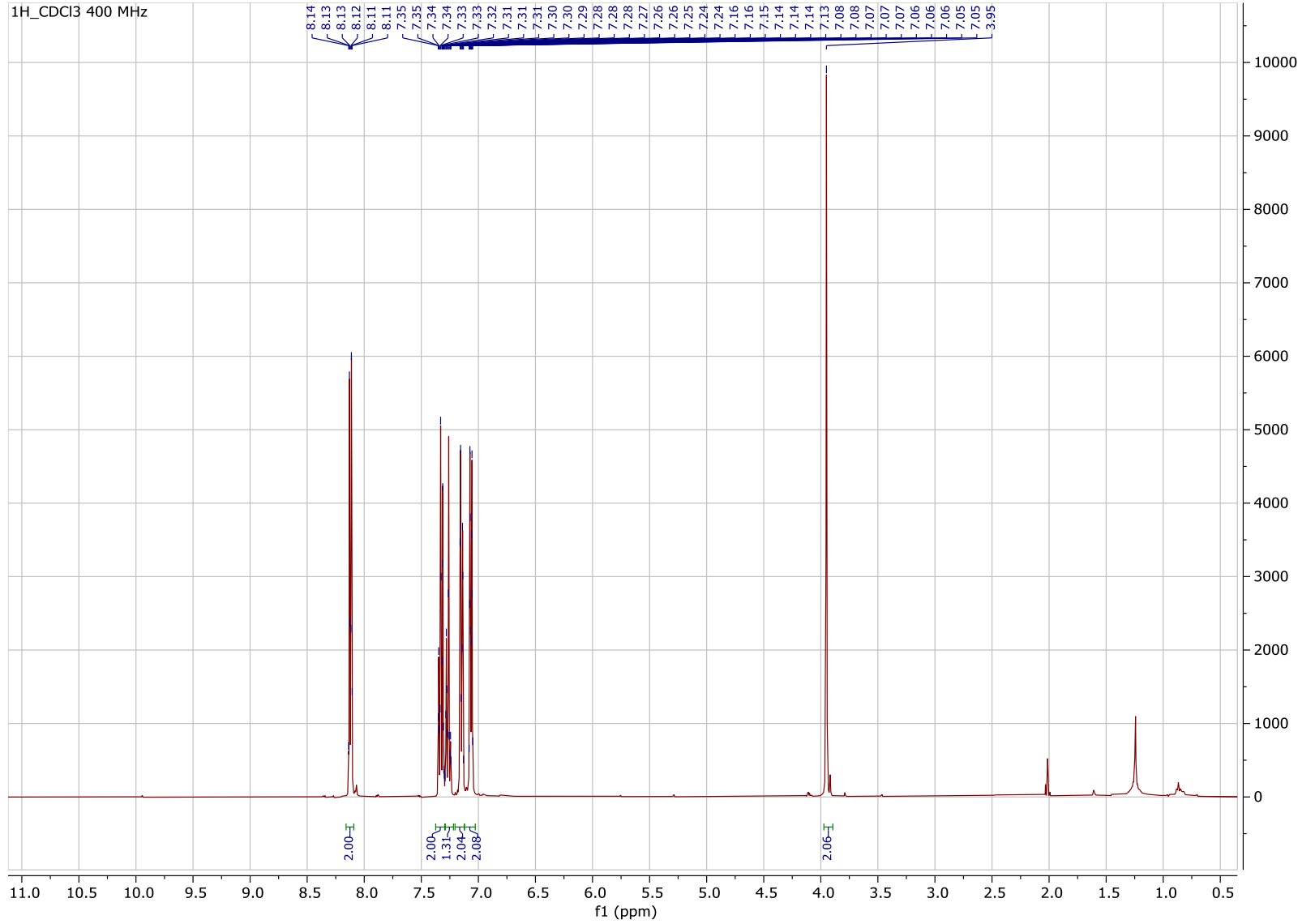


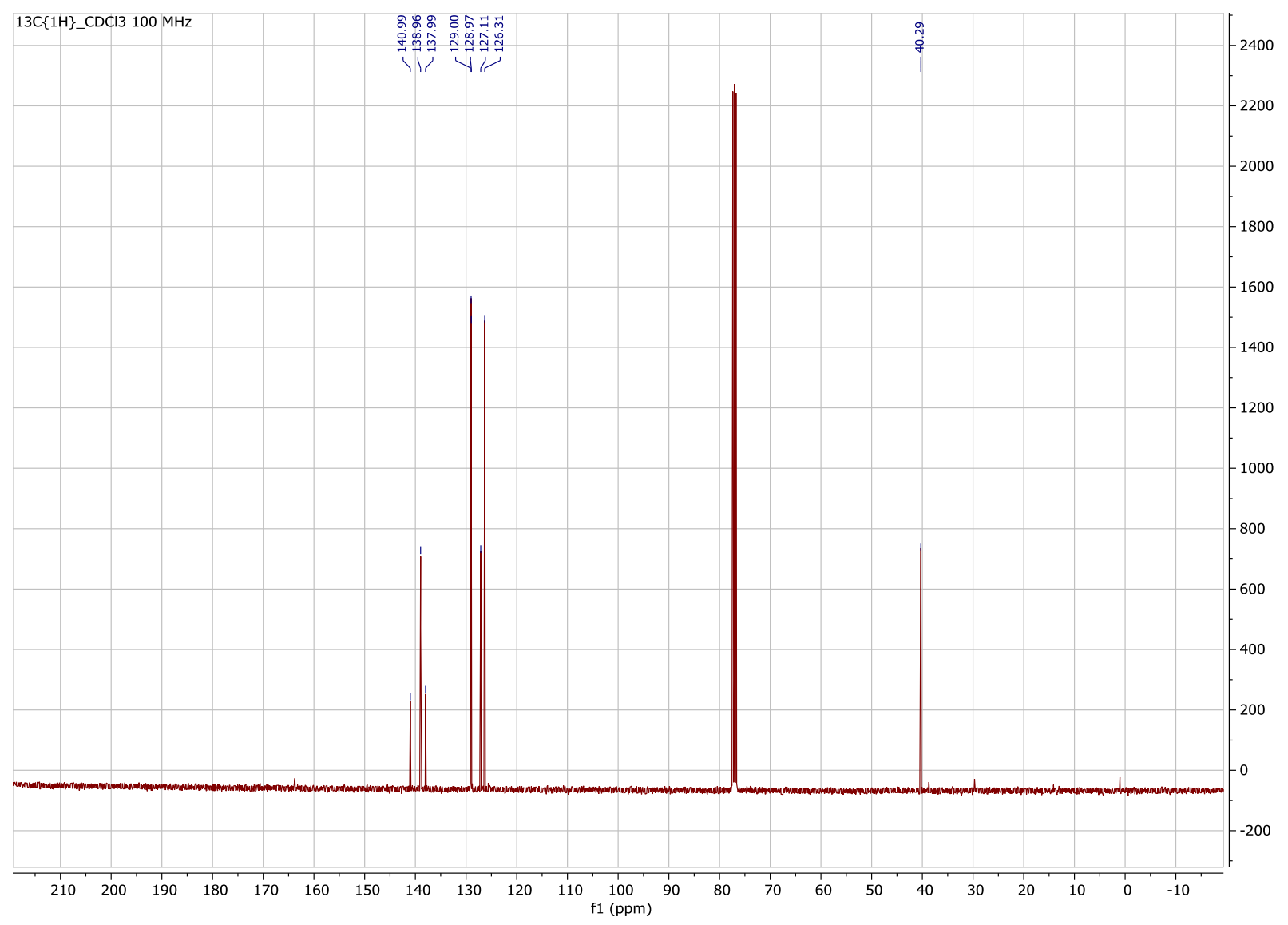




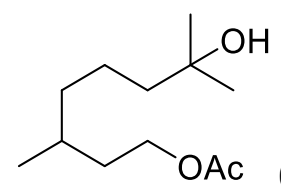

\section{6a - 7-Hydroxy-3,7-Dimethyloctyl Acetate}

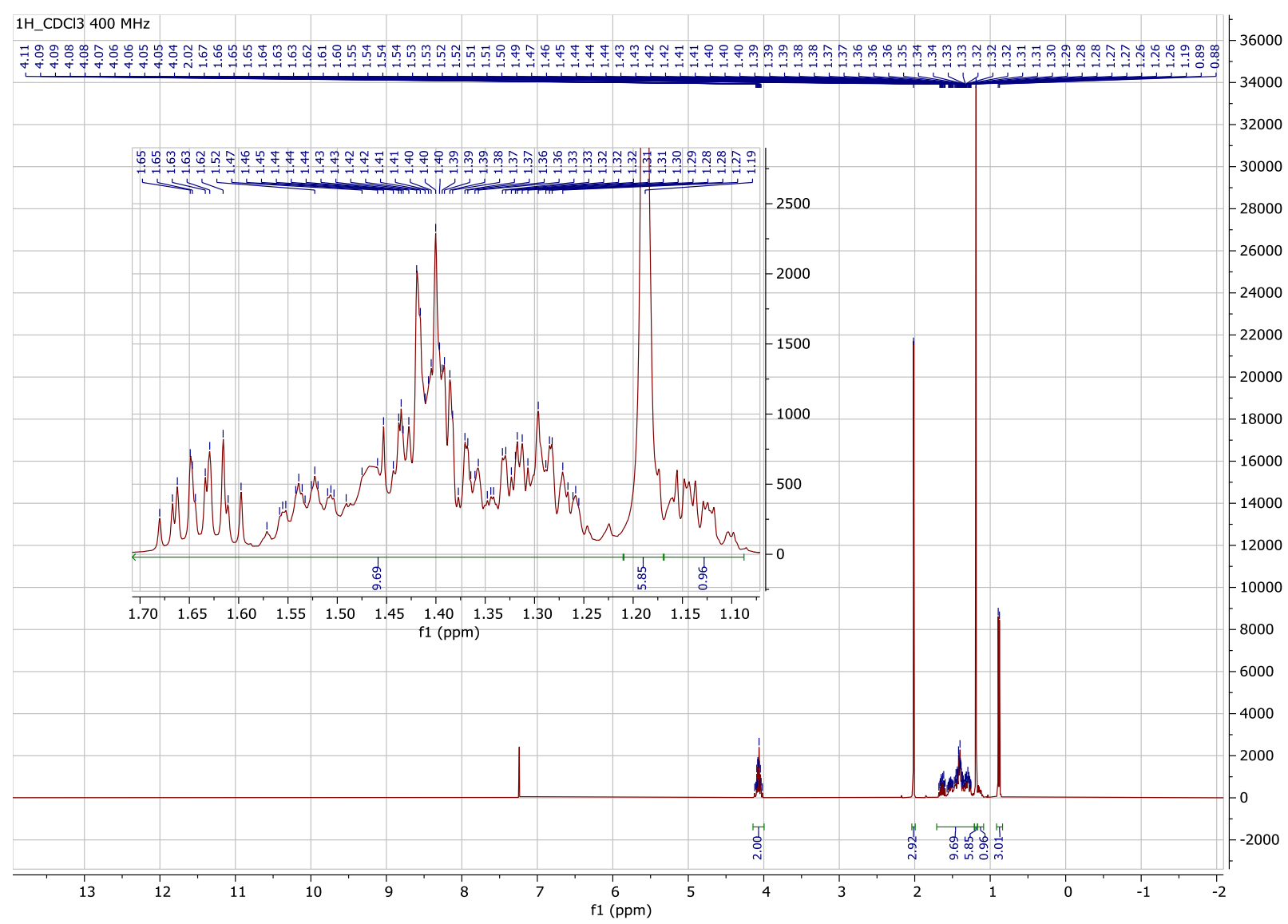




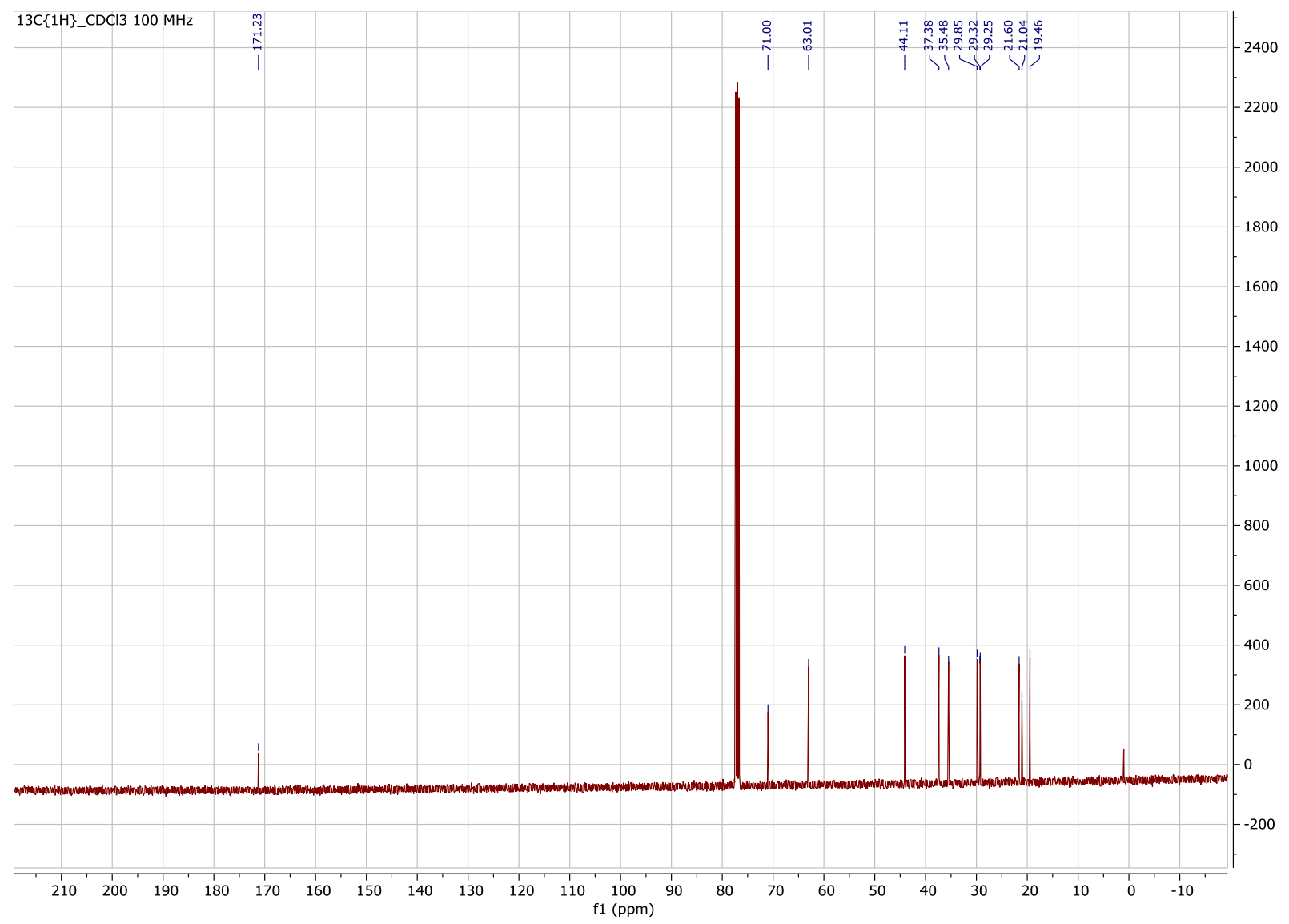




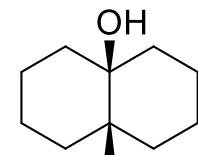

H 6b-Cis-9-Decalol

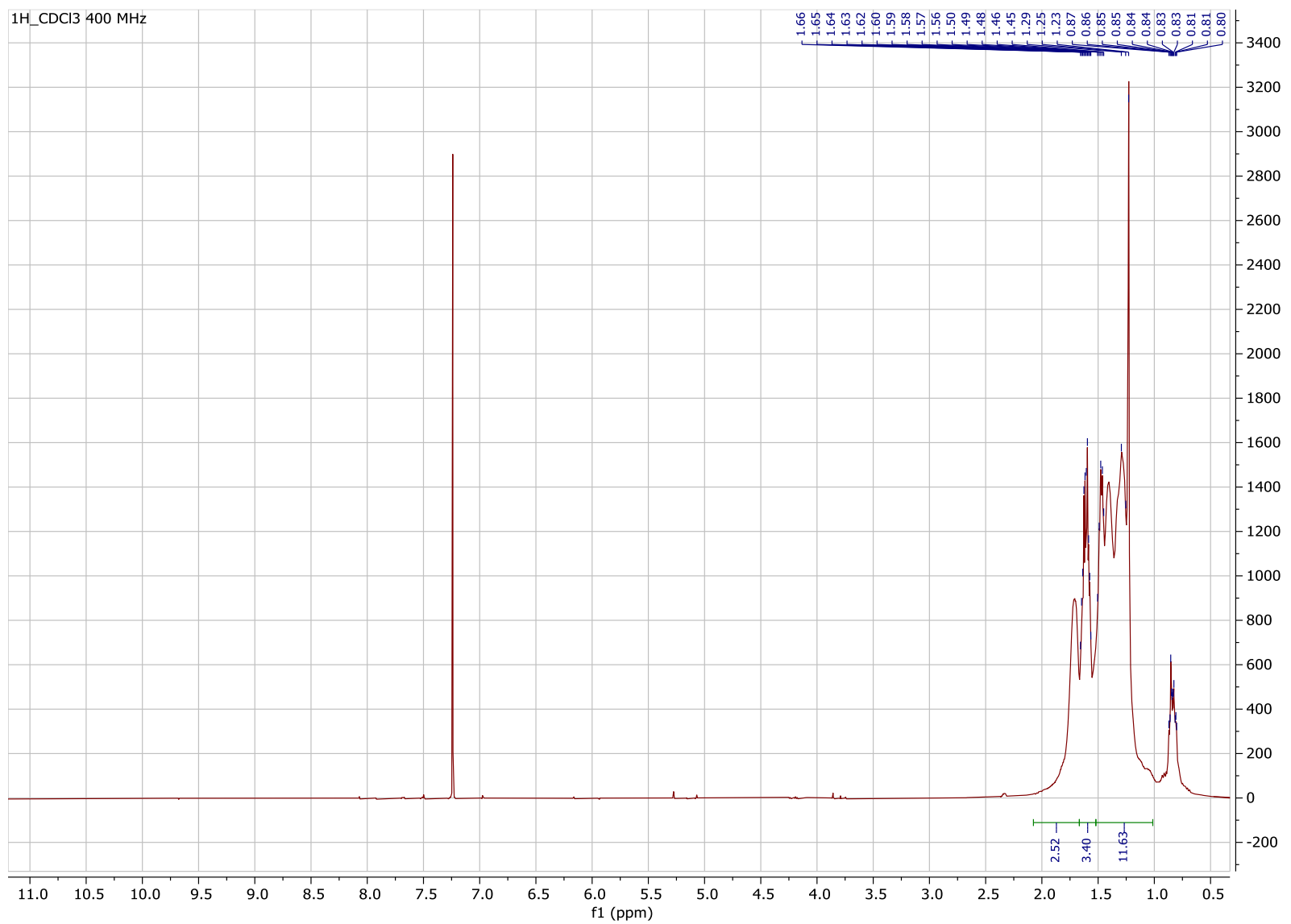




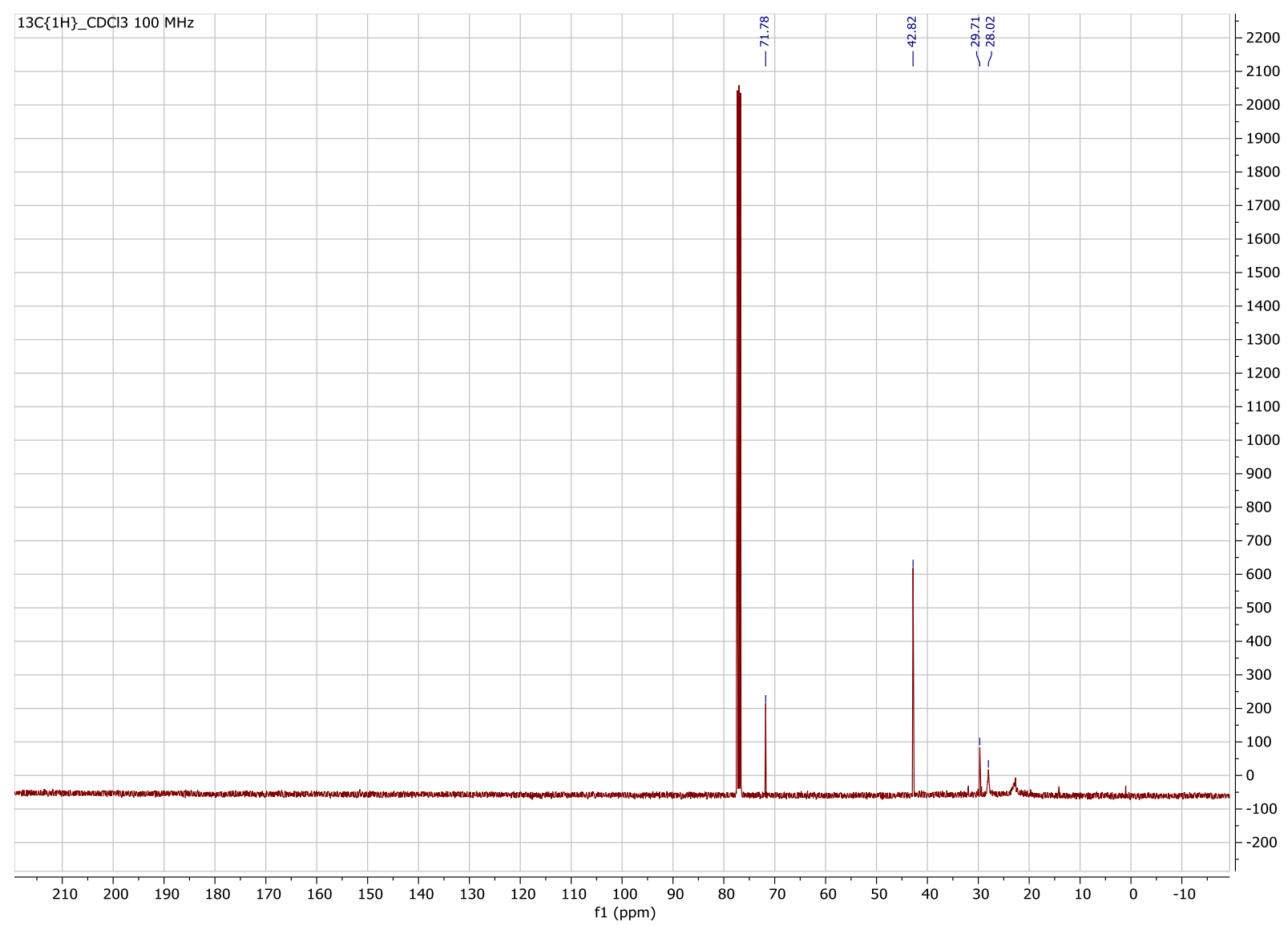


$\sim^{\mathrm{O}}$

8a - Cyclohexane Carboxylic Acid

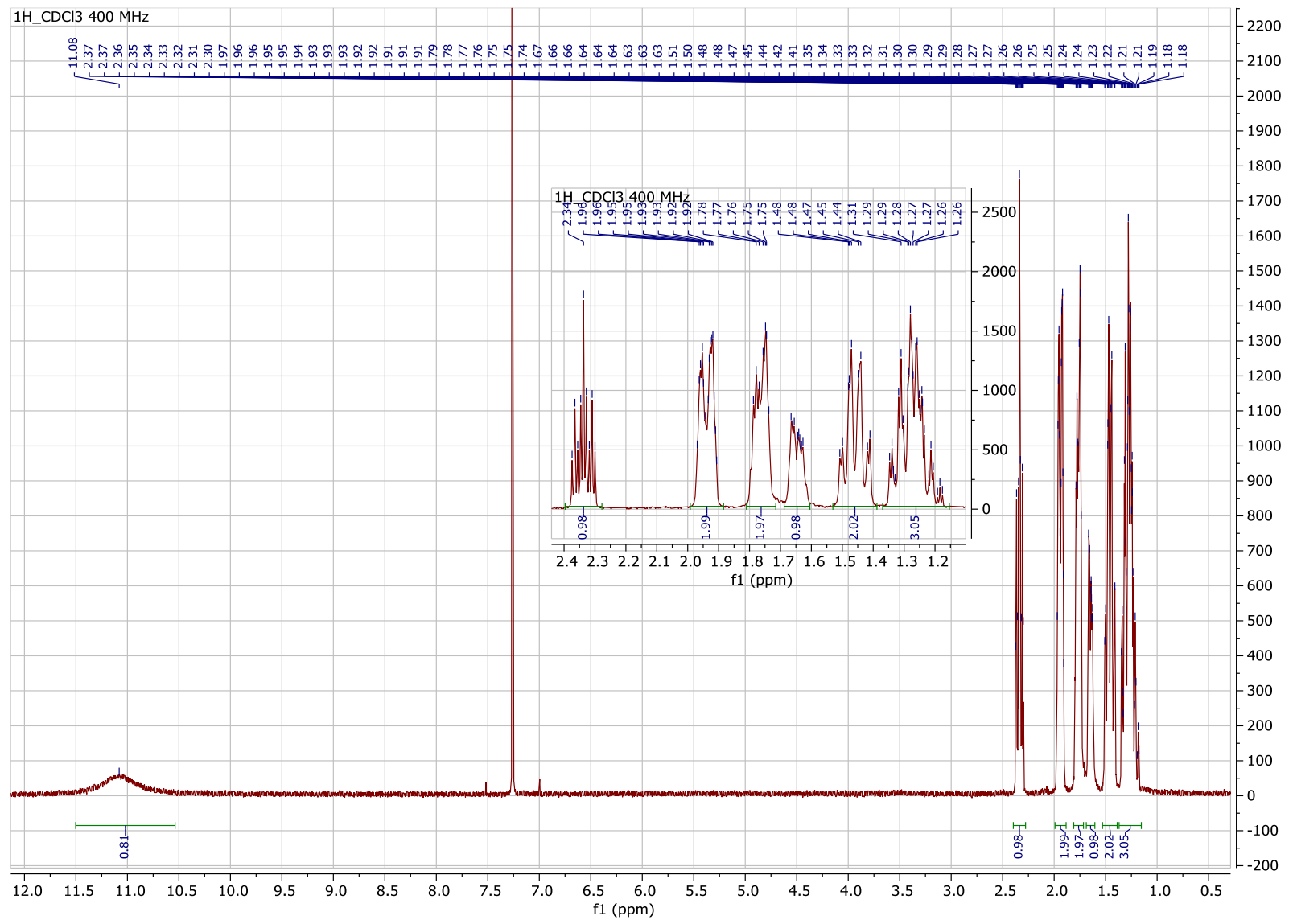




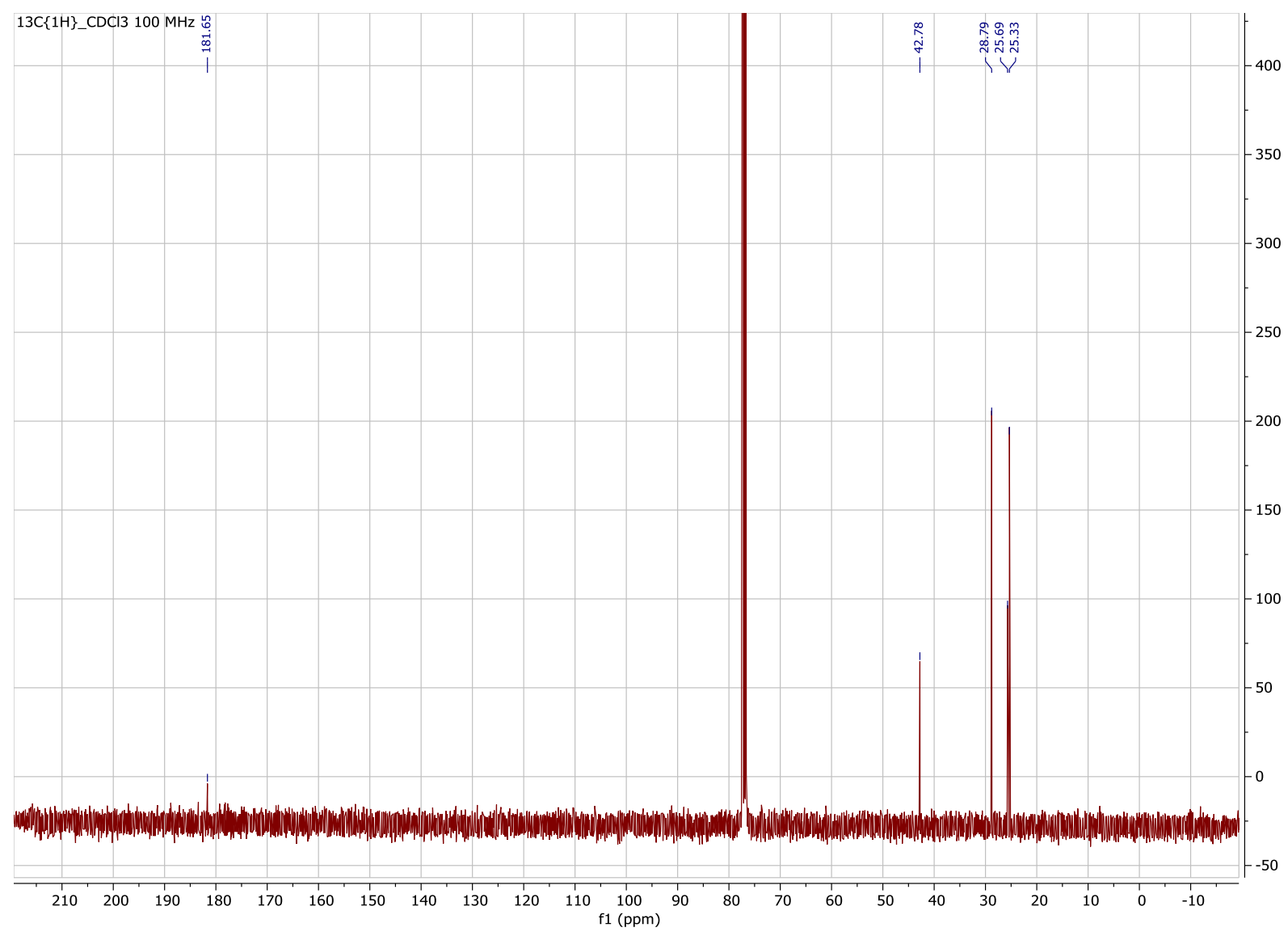



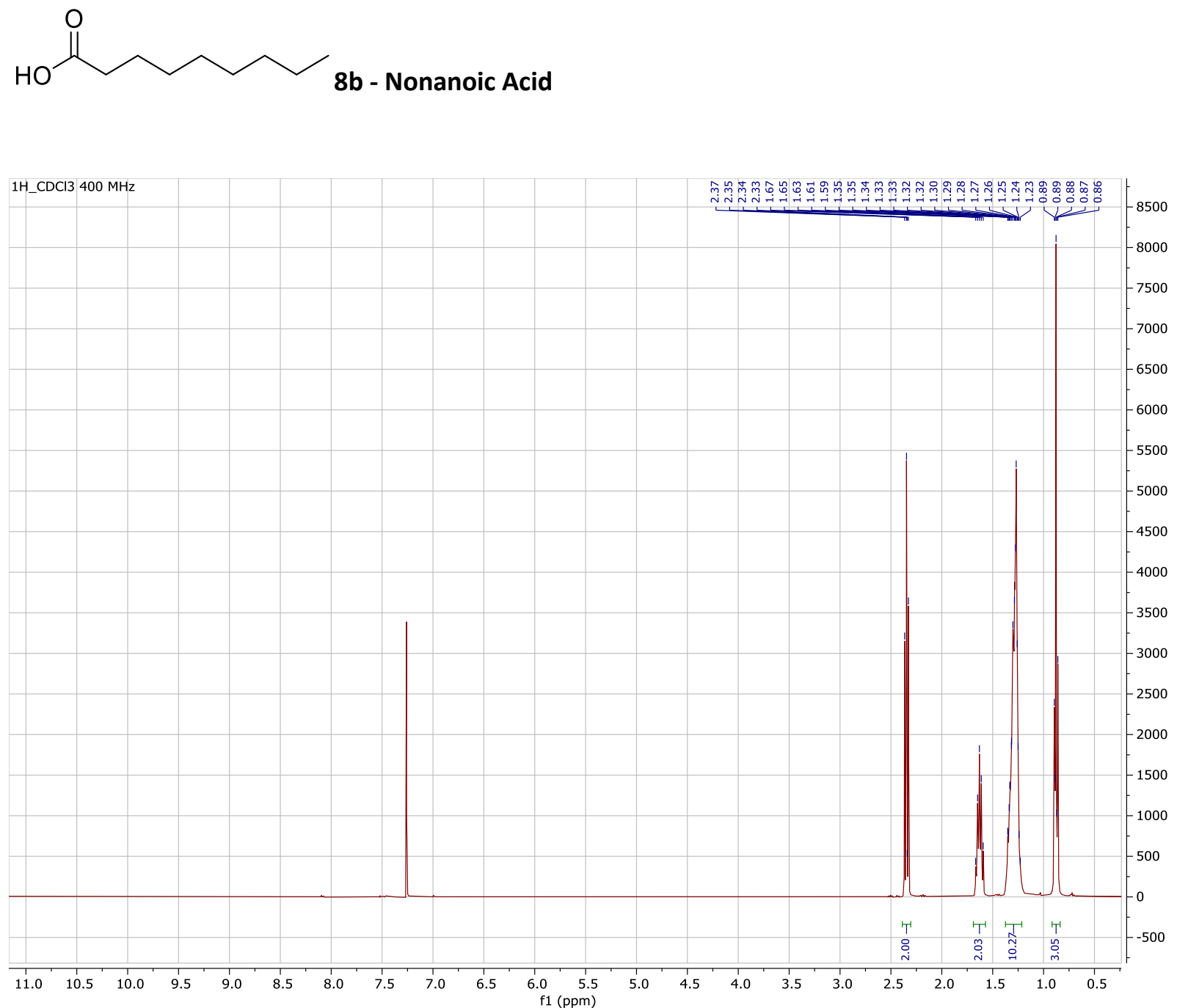


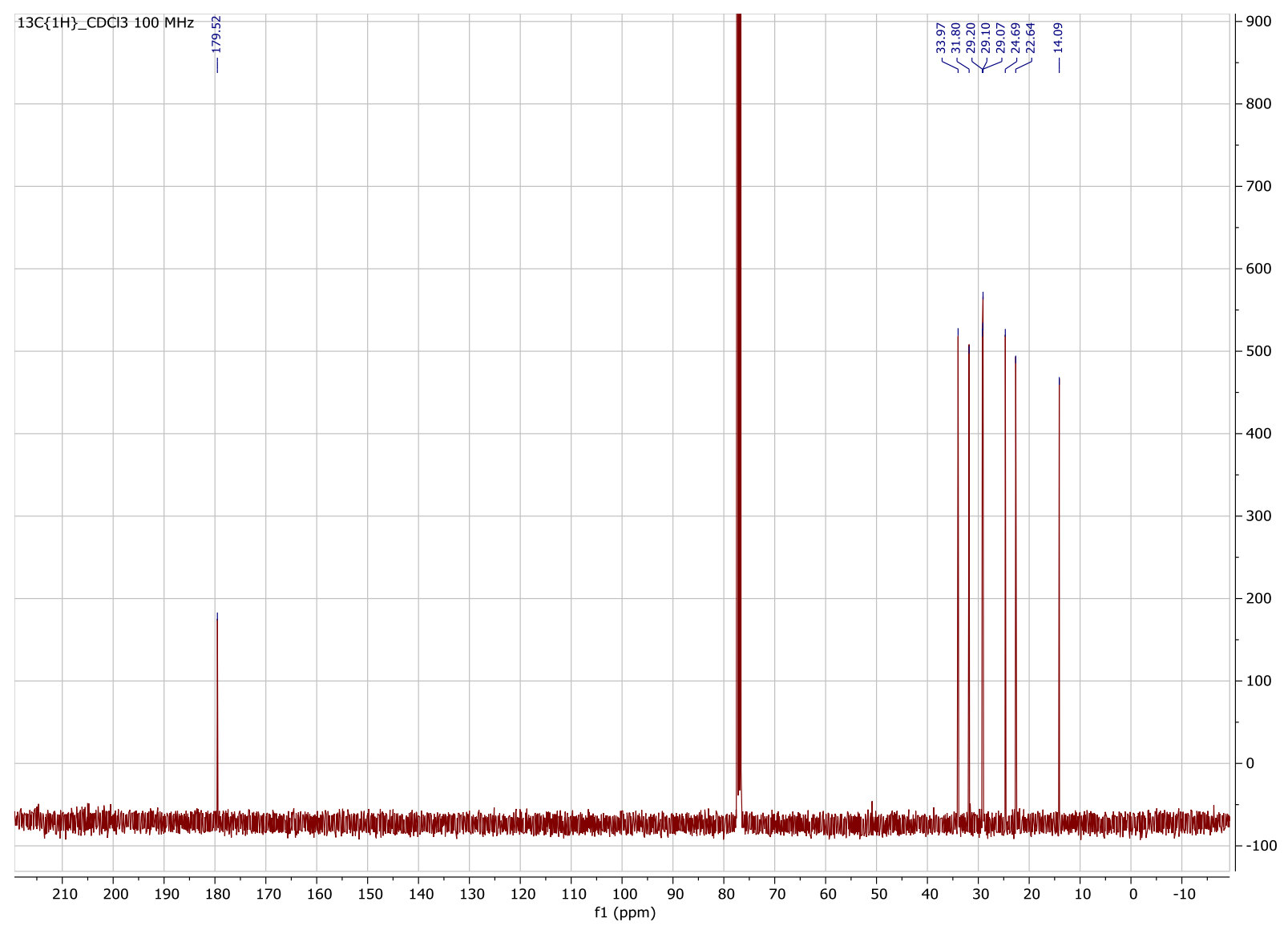

